\title{
EDIFICIO DE PROTECCIÓN DE LAS TERMAS ROMANAS DE SANT BOI DE LLOBREGAT (BARCELONA, ESPAÑA)
}

\author{
(BUILDING A PROTECTIVE STRUCTURE AROUND THE ROMAN BATHS AT SANT BOI DE \\ LLOBREGAT, BARCELONA. SPAIN)
}

Antoni González Moreno-Navarro, Arquitecto

Jefe del Servicio de Patrimonio Arquitectónico Local de la Diputación de Barcelona

ESPAÑA

Fecha de recepción: 16-IX-99

\section{RESUMEN}

Las termas romanas de Sant Boi de Llobregat, construidas hacia el año 200 dC y descubiertas en 1953, son una de las instalaciones de este tipo mejor conservadas de Cataluña. Algunos de los muros alcanzan casi cinco metros, hecho poco habitual, y se mantienen seis de las siete salas de las que constaron, con restos muy interesantes. Casi abandonadas desde 1975, en 1988 se inició su recuperación definitiva y la construcción de un edificio que las protegiera y permitiera la visita pública. En su presentación se ha confiado toda la emoción del espectador a la contemplación directa de las ruinas y se ha renunciado a artificios, como audiovisuales efectistas o realidad virtual.

La ciudad de Sant Boi de Llobregat, situada en la vertiente superior del actual delta del río Llobregat, dista unos 13 $\mathrm{km}$ de la capital de Cataluña, Barcelona. El municipio tiene en la actualidad casi ochenta mil habitantes. En la antigüedad, el altozano que ocupa su actual centro histórico, presidía la desembocadura del río, por lo que constituía un lugar estratégico y especialmente apto para proteger un puerto. La primera ocupación humana del lugar que se conoce data de mediados del siglo IV aC y corresponde a un poblado de layetanos, la tribu ibera que habitaba el tercio central de la costa catalana. Doscientos años más tarde, el lugar pertenecía al territorio adyacente a la ciudad de Barcino (primer núcleo de Barcelona) y fue ocupado por una villa romana -cuyos restos han sido descubiertos en diversos lugares del centro histórico-, formada por la

\section{SUMMARY}

The roman baths at Sant Boi de Llobregat were built some time around the year 200 BC and came to light in 1953. They are some of the best baths of this type to be found preserved in Catalonia. Some of the walls are almost five metres high, which is rare. There were originally seven rooms, and interesting remains of six of them can still be seen today. The baths were virtually abandoned in 1975, but restoration began in 1988, including the construction of a building to protect them and to enable the public to visit them. The design of the presentation trusts entirely to the emotion felt on seeing these ruins at first hand, and other elements, such as audio-visual effects or virtual reality, have been rejected. residencia del propietario y su familia, las dependencias agrícolas y las tierras de cultivo.

Gracias a la exportación de los excedentes de la explotación agrícola (desde alrededor del año $30 \mathrm{aC}$ se producía vino que se exportaba a las Galias e Italia), la villa se enriqueció y hacia el año 200 de nuestra era se amplió su área residencial y se llevaron a cabo numerosas reformas en las demás dependencias. Fue hacia esa fecha cuando se construyó el edificio termal.

\section{Las termas romanas}

Las primeras termas (thermae) se localizan en la región de la Campania, en torno a la actual ciudad de Nápoles 
(Italia), datables a finales del siglo $\mathrm{V}$ aC. Estaban asociadas a las palaestra (lugares de carácter público donde se practicaba gimnasia) y consistían en pequeñas dependencias con una bañera individual de agua templada que se usaba después de los ejercicios. En el siglo III aC aparecen, formando parte de la construcción de estas bañeras, los primeros vestuarios -apodyteria- y unas salas con una bañera de agua tibia-tepidaria.

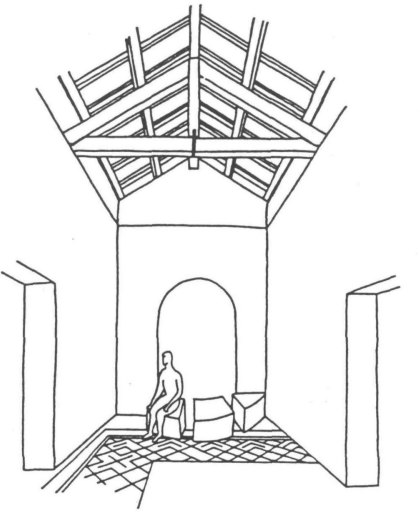

Restitución ideal del apodyterium.

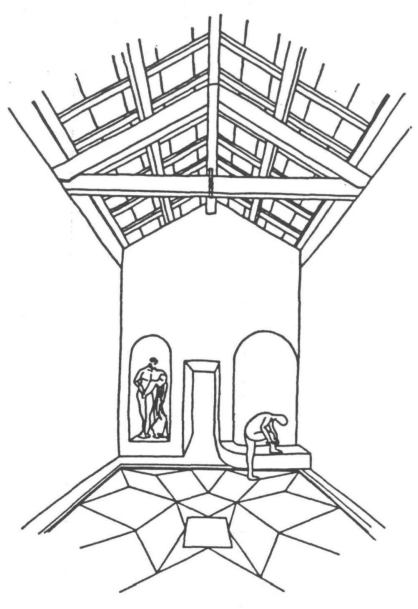

Restitución ideal del frigidarium.

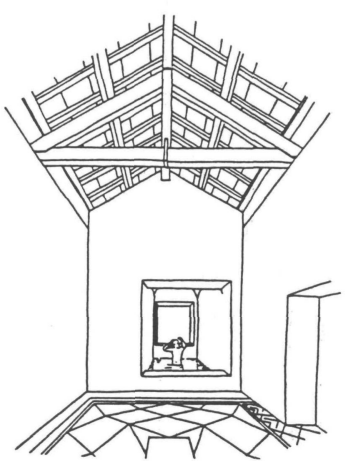

Restitución ideal de la piscina.

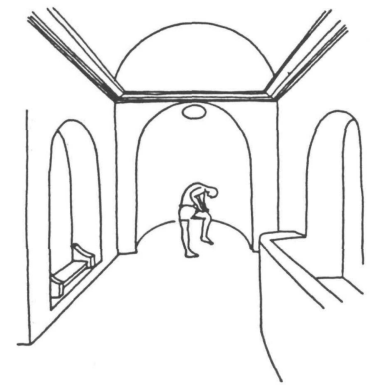

Restitución ideal del tepidarium.

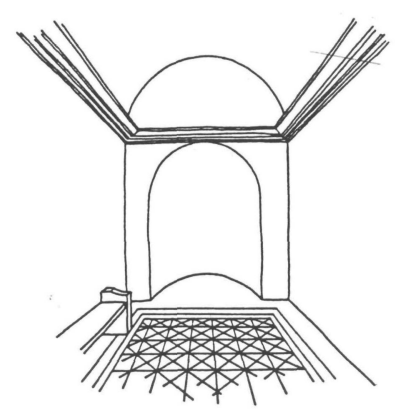

Restitución ideal del sudatorium.

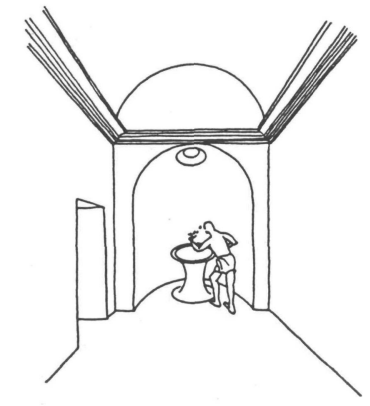

Restitución ideal del caldarium.
En estos baños públicos, además de cumplirse las funciones higiénicas y terapéuticas que les eran propias, se desarrollaba buena parte de la vida social y servían de salón de belleza. Más tarde, en las residencias privadas de categoría se incorporaron estancias termales más o menos suntuosas, cuyo uso se extendió a lo largo del Alto Imperio.

El recorrido de las termas se iniciaba en el apodyterium o vestuario, donde los usuarios cambiaban sus vestiduras por una pieza de tela sujeta a la cintura y su calzado por unas zapatillas de madera. De ahí se pasaba al tepidarium, donde los bañistas se aclimataban al calor (entre $25^{\circ}$ y $30^{\circ}$ ) y untaban su piel con aceites perfumados. A continuación, se entraba al laconicum (en el caso de las termas más antiguas) o al sudatorium, en las que el cuerpo transpiraba en un ambiente, seco o húmedo, a unos $80^{\circ}$. El primero se calentaba con braseros $\mathrm{y}$, el segundo, mediante un hypocaustum, un sistema subterráneo de calefacción por aire caliente que, proveniente de un horno, pasaba bajo el suelo de las estancias (denominado suspensura, apoyado en pilarcillos de ladrillo, pilae, que descansaban sobre un pavimento inferior o área). $\mathrm{El}$ aire caliente podía también transmitirse a través de tubuli o tegulae mammatae (conductos de piezas de arcilla adosadas a las paredes), que calentaban los muros y permitían el tiro. El hypocaustum apareció a comienzos del siglo I aC. Esta

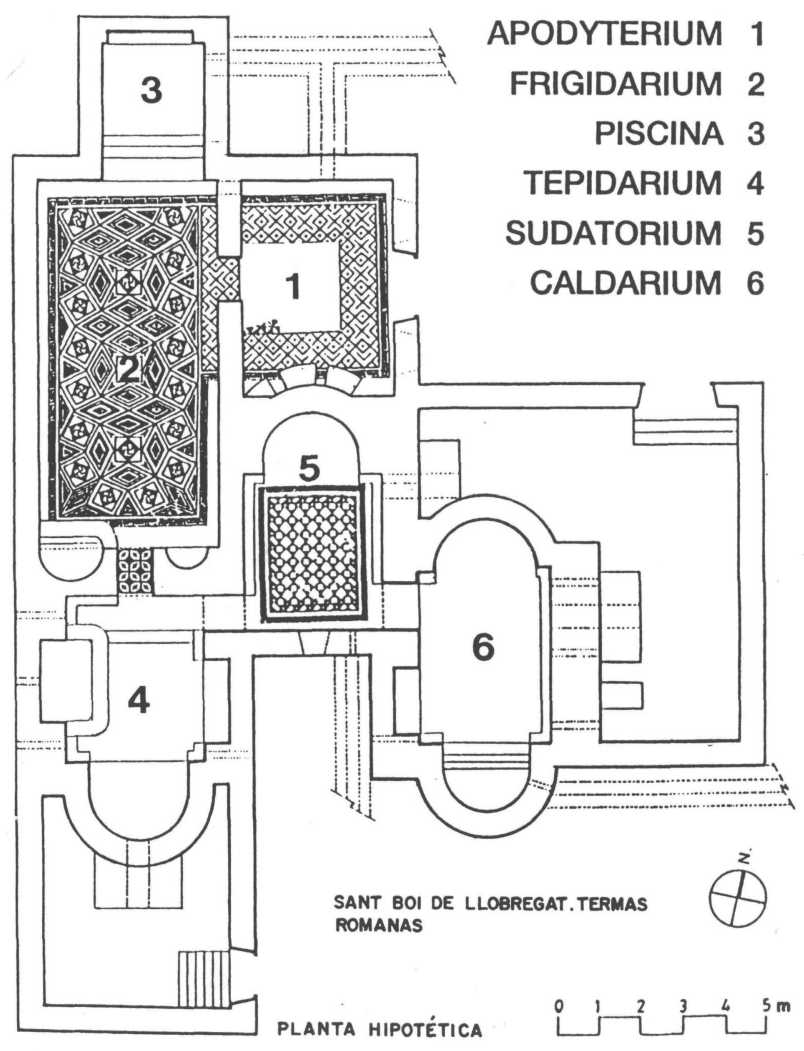

Restitución ideal de la planta del edificio termal en la época del Bajo Imperio (Dibujos: Txetxu Sanz). 

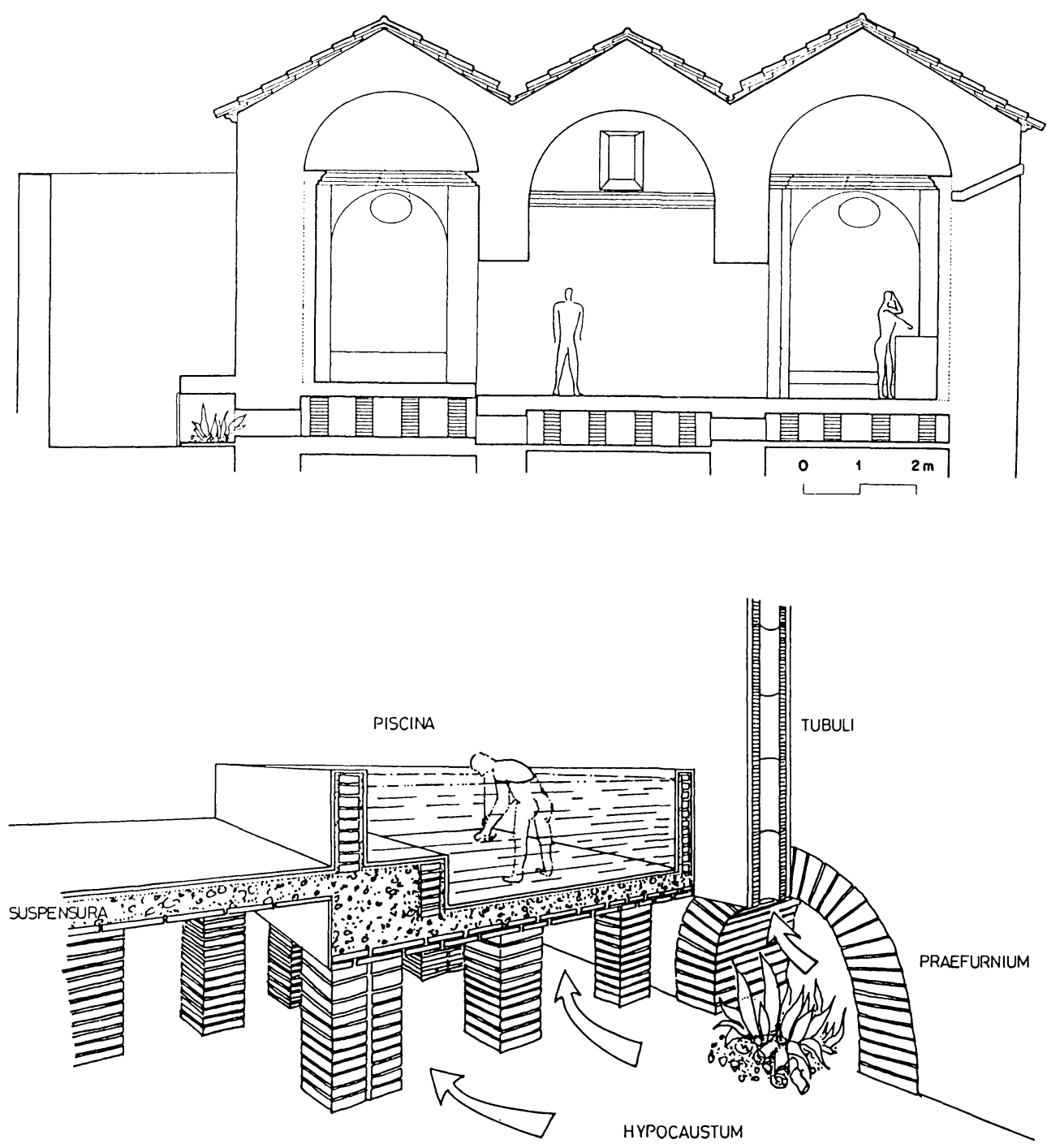

Restitución ideal de la sección transversal de las estancias cálidas de las termas (praefurnium, caldarium, sudatorium y tepidarium).

solución técnica permitió construir baños independientes y ampliar sus dimensiones, pudiendo calentarse espacios más grandes sin problemas de intoxicaciones. Fue a finales del siglo I aC, cuando el nuevo sistema de calefacción se extendió a las paredes mediante la utilización de placas cerámicas. Hacia el año 150 de la era, estas piezas se substituyeron por canalizaciones de forma rectangular - tubuli- y de cerámica, lo que permitió que circulara más aire caliente por los muros y, por lo tanto, que aumentara la eficacia del sistema. En el caldarium, la siguiente sala, se registraba una humedad cercana al $80 \%$ y una temperatura de $55^{\circ}$ (el agua de la bañera, $40^{\circ}$ ). En una pila con agua fría situada en una exedra, se podían hacer abluciones. Antes de salir del recinto, los bañistas permanecían en la piscina del frigidarium para cerrar los poros de la piel. Mientras propietarios e invitados completaban el circuito, el servicio alimentaba los hornos situados en una dependencia anexa, preferentemente con madera de olivo.
Las termas de Sant Boi, de carácter privado, estaban compuestas en su origen según el esquema clásico de unas termas de desarrollo lineal, por siete salas, en dos bloques (el de las salas dotadas de calefacción y el de las de ambiente frío). En su construcción se utilizaron la mampostería de caliza y pizarra, y el mortero de arena, cal y gravilla. Los pavimentos inferiores de los hipocaustos, de opus signinum, apoyan directamente sobre el terreno, y los superiores tienen una capa inferior de ladrillos bipedalis recubierta por un rudus y por una capa de fino mortero y, sobre ellas, el pavimento de mosaico (opus tessellatum) o de mármol (opus sectile).

La villa romana de Sant Boi, incluido el edificio termal, funcionaba a pleno rendimiento en el siglo $\mathrm{V}$ y es muy probable que así fuera también durante la época visigótica, es decir, hasta bien entrado el siglo VIII. No conocemos la fecha en que pudo abandonarse definitivamente la 
explotación agrícola y el uso de las edificaciones, pero sí sabemos que una gran parte de las dependencias del edificio termal estaban aún en buen estado en el siglo XVII, aunque abandonadas. Por aquel entonces se construyó encima de esos restos una casa, utilizándose algunas de aquellas dependencias como sótano del nuevo edificio.

\section{La historia reciente}

La memoria de la villa romana y de las termas se perdió en la oscuridad de la historia. Aun así, hasta bien entrado el siglo XIX, subsistió un topónimo que guardaba con ellas una relación (posiblemente ya indescifrable), derivada de nuestra ancestral costumbre de identificar la antigüedad con nuestro pasado musulmán: la calle adyacente al lugar que ocuparon los antiguos baños, en aquel momento enterrados, se denominaba aún "de la Mezquita". Un topónimo que se perdió en el siglo XX, pero que serviría para que a mitad de esa centuria se soldara la solución de continuidad de la memoria histórica truncada.

El año 1953, un estudioso de Sant Boi, Carles Martí Vila, advirtió que un documento de 1826, escrito por el servita fray Pere Puig y conservado en el Archivo Parroquial de Sant Boi, hacía referencia a que en aquella zona de la población existían "vestigios de una mezquita». El documento citaba también la existencia en aquel lugar de pavimentos de azulejos enterrados bajo «doce o trece palmos» de tierra. Estos datos, puestos en relación con el topónimo ya en desuso, sugirieron a Carles Martí la posibilidad de encontrar en aquel lugar restos antiguos acompañados de mosaicos. Su compañero de afición, Ramon Mas Campderrós, junto a otros entusiastas diletantes, empezaron enseguida la excavación, patrocinada por el municipio, y al poco tiempo encontraron el frigidarium de los baños, que contenía el mosaico de mayor tamaño y mejor conservado, lo que permitió precisar la antigüedad y el tipo de los restos escondidos en aquel lugar durante tantos siglos.

Entre 1954 y 1959 se hizo cargo de la dirección técnica de la investigación Josep de Calassanç Serra Ràfols, conservador del Museo Arqueológico, dependiente de la Diputación de Barcelona, y comisario provincial de Excavaciones, siempre con la colaboración de Ramon Mas. Las excavaciones fueron subvencionadas por diversos organismos públicos $\mathrm{y}$, sobre todo, por el Ayuntamiento, que adquirió el solar en 1955. La muerte en 1971 del director de la investigación, Serra Ràfols, impidió que los resultados de la excavación tuvieran la difusión necesaria.

A petición del Ayuntamiento, el Servicio de Catalogación y Conservación de Monumentos de la Diputación de Barcelona, bajo la dirección del jefe de servicio, el arquitecto Camilo Pallàs Arisa, intervino a partir de 1956 en las tareas de carácter constructivo y realizó algunos proyectos para cubrir los restos hallados y diversas obras, siempre parciales o de emergencia, hasta que en 1975 el yacimiento quedó prácticamente abandonado y sin protección eficaz. Muchos de los vestigios excavados se deterioraron irreversiblemente.

En 1988, el nuevo Ayuntamiento, consciente de la gravedad de aquel abandono y de la conveniencia de que las termas pudiesen ser visitadas, solicitó a la Diputación que volviese a intervenir y proporcionase el asesoramiento técnico y científico y el apoyo económico necesario para afrontar las complejas obras precisas. Aceptada la solicitud, el Servicio del Patrimonio Arquitectónico Local se encargó de las tareas de restauración, protección y exposición pública de los restos. ${ }^{1}$

\section{Prosecución de la investigación histórica}

Esta segunda etapa de intervención del Servicio de la Diputación de Barcelona comenzó en 1989 con los estudios previos de carácter histórico, que incluyeron una investigación documental con el fin de precisar el alcance de las intervenciones anteriores, y nuevas campañas de estudios arqueológicos.

Estos estudios tuvieron como objetivo determinar la extensión y situación de los restos en el solar (y la probable continuidad del yacimiento fuera de la finca municipal), así como el área exacta que había sido ya objeto de las investigaciones precedentes, para establecer una secuencia estratigráfica que relacionase la totalidad del yacimiento, y, por último, hacer una restitución hipotética de todos los elementos del antiguo edificio termal, bien para poder reconstruirlos in situ, si así se decidía, o para exponerlos a los visitantes mediante maquetas u otros procedimientos didácticos.

Los trabajos de excavación afectaron, por lo tanto, además de las zonas anteriormente excavadas, a la parte del yacimiento aún intacta, es decir, el solar situado a poniente de los restos (fue así como se pudo datar el recinto), y el entorno inmediato a éstos por levante y mediodía, donde fue posible una excavación más extensiva, aunque gravemente condicionada por la seguridad de los edificios o vías que rodeaban las termas.

Finalmente, se hicieron una prospección por geo-radar, una serie de sondeos estratigráficos en zonas adyacentes

\footnotetext{
${ }^{1}$ Para más información sobre las termas de Sant Boi y la intervención del SPAL, ver: "Edificio de protección de las termas romanas. Sant Boi de Llobregat, en A. González, La restauración objetiva. Método SCCM de restauración monumental. Memoria SPAL 1993-1998, vol. 2, pág. 261, Barcelona, Dip. de Barcelona, 1999; Albert López Mullor, Imma Estany: "L'excavació a l'àrea de les termes romanes de Sant Boi de Llobregat" (campanyes 1989-1991), en Quaderns Cientifics $i$ Tècnics, 5, Dip.de Barcelona, 1993; Raquel Lacuesta: La intervenció de 1953-1975 a les termes romanes de Sant Boi de Llobregat (Barcelona): SPAL, 1999 (en prensa).
} 
a los restos, trabajos de exploración arquitectónica de éstos y se procedió a desmontar las edificaciones construidas en los años sesenta para proteger el tepidarium y el frigidarium.

\section{Criterios de la intervención}

Restaurar, proteger y exponer al público los restos romanos fueron, como he dicho, los objetivos señalados en esta intervención del SPAL. Pero precisar el cómo hacerlo no fue inmediato, y se fue definiendo paralelamente a los trabajos de investigación, incluso se redefinió varias veces en el curso de la obra posterior (condicionada a la postre por una ampliación del solar inicial), en un proceso que no fue ni lineal ni sencillo.

Las respuestas a los tres objetivos estaban muy condicionadas unas con otras y ninguna tenía un punto de partida diáfano: las opciones de cómo restaurar los restos (consolidarlos únicamente, reconstruirlos según datos científicos, eliminar o no de ellos las aportaciones de las restauraciones anteriores, etc.) estaban condicionadas al cómo exponer esos restos, y viceversa (si el espectador debía acceder a ellos para pasearse y comprender así su espacio original; o si debía contemplarlos desde fuera, directamente y tal como eran, o reconstruidos virtualmente mediante artilugios tecnológicos, etc.); $y$, en ambos casos, las decisiones estaban, a su vez, condicionadas por cómo proteger, tanto los restos como a los visitantes (mediante un edificio climatizado, una simple cubierta, una sala anexa a un museo o un museo con un programa autónomo, etc.). A su vez, el carácter de esta instalación no dependía únicamente de planteamientos conceptuales, sino también de factores organizativos, técnicos y administrativos ajenos (ya que el presunto museo, o lo que finalmente fuera aquello, dependía del municipio y éste varió varias veces de responsables y de pareceres).

El conjunto final de los criterios establecidos, resultado como puede comprenderse de decisiones sucesivas (condicionadas además todas, como se ha dicho, por avatares de diverso tipo), fue éste: en primer lugar, conservar los restos de las termas, una vez limpiados, consolidados y puestos en valor, en la forma y el volumen en que habían llegado a nuestros días, sin eliminaciones ni añadidos (aunque, por supuesto, visualmente "crecidos", al haberse sacado a la luz restos no excavados con anterioridad); en cuanto a la visita, establecer un recorrido externo a los restos, para evitar su deterioro, y confiar la comprensión de la historia y la arquitectura de las termas a procedimientos didácticos tradicionales; $y$, por último, en cuanto a la protección, levantar un edificio, de espacio único, que permitiera la conservación de los restos y facilitara la visita; un edificio, no concebido como museo, sino como sala monográfica de una instalación de ámbito mayor (en cuanto a contenido e instalaciones) y, en consecuencia, con un programa exclusivo de visita, sin otro tipo

(c) Consejo Superior de Investigaciones Científicas Licencia Creative Commons 3.0 España (by-nc) de servicios o actividades, lo que permitía considerarla como una sala no estanca, semi-abierta, no climatizada.

Estos criterios programáticos encerraban otros, menos explícitos y más conceptuales: la arquitectura histórica a proteger y mostrar (el auténtico monumento, los restos de las termas) y la nueva arquitectura (el edificio protector) debían diferenciarse y respetarse mutuamente sin ambigüedad. Ni el monumento podía ser agredido en nada por la arquitectura nueva (ciertamente, subsidiaria de él), ni ésta podía estar condicionada estéticamente por aquél. Y el espectador debía intuir esa diferencia y respeto, sintiendo (sumadas, pero no confundidas), las emociones que pudieran producirle los restos históricos en cuanto tales (como reliquia, como documento) y, por otra parte, la nueva arquitectura (con sus posibles valores espaciales, formales y de uso).

\section{LA RESTAURACIÓN DE LOS RESTOS DE LAS TERMAS}

A pesar de los avatares sufridos por su fábrica, la de Sant Boi es una de las instalaciones termales romanas mejor conservadas de Cataluña (la altura de sus muros, por ejemplo, en ciertos puntos llega a los $4,80 \mathrm{~m}$ por encima del pavimento inferior del hipocausto, hecho nada habitual).

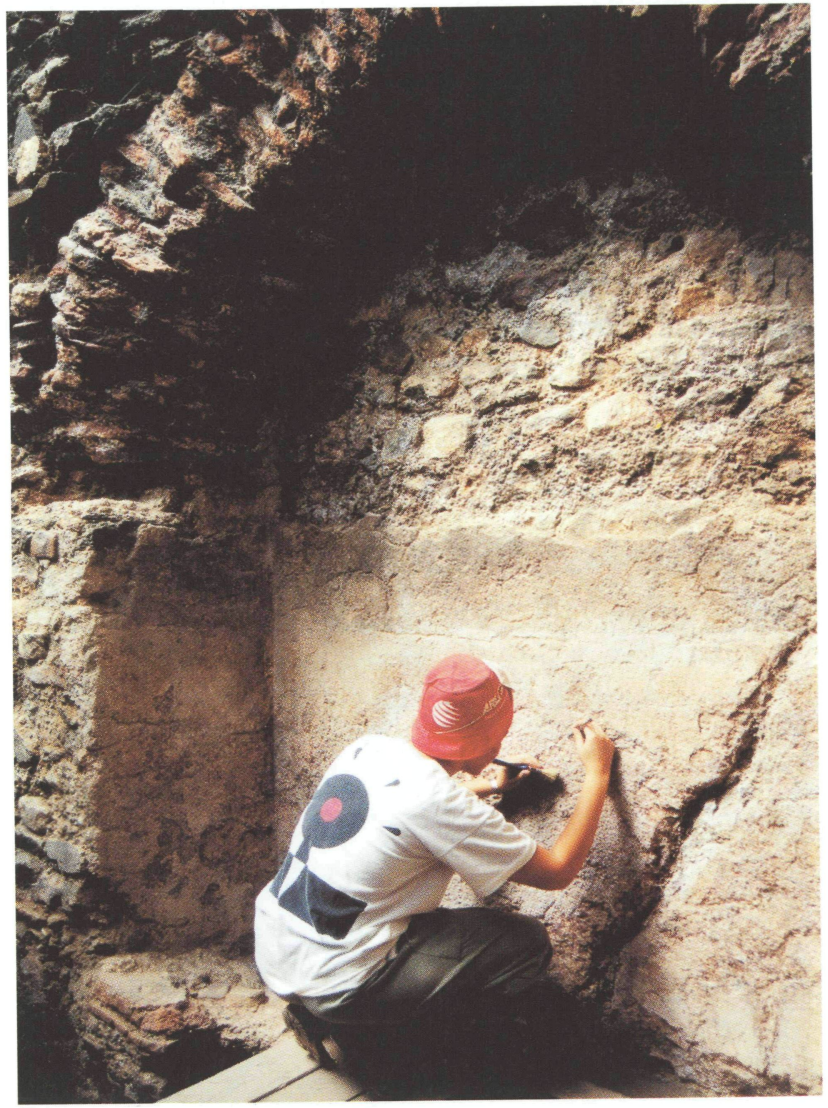

Limpieza y consolidación de los revestimientos de los muros del tepidarium. Foto Montserrat Baldomà (MBS). Julio de 1998.

http://informesdelaconstruccion.revistas.csic.es 
Han llegado hasta nosotros, por otra parte, seis de las siete salas, en las que permanecen elementos muy significativos. El apodyterium conserva restos del pavimento de mosaico decorado con una orla con flores y una cenefa en forma de greca, con decoración geométrica realizada en blanco y negro; el frigidarium, la totalidad del muro de mediodía, en el que se abren sendas hornacinas, la mayor con una pequeña bañera a sus pies, y un mosaico con decoración geométrica en blanco y negro, compuesta por rombos y cruces gamadas inscritos en una cenefa en forma de greca; la cella piscinalis conserva todo su recinto (descubierto durante los trabajos de 1989), con sus dos escalones interiores; el tepidarium o cella tepidaria, el pavimento inferior (área) casi intacto, y, parcialmente, el pavimento superior (suspensura) y los pilarcillos de sustentación; las dos estancias cálidas, assa sudatio o sudatorium, restos del pavimento superior, que fue de mosaico (el inferior, que apareció intacto en 1957, se deterioró posteriormente), y la cella caldaria o caldarium, sendas exedras a tramontana y mediodía, cuyas paredes laterales presentan hornacinas, la de levante con restos de un alveus o pequeña bañera en el interior. También se conservan vestigios de los muros que delimitaban a levante y a poniente la dependencia de servicios de los hornos del tepidarium, el caldarium y el sudatorium, y de los desagües de las dos últimas estancias.

Al iniciar la intervención en los restos, en 1989, aún no se había trazadoun criterio definitivo de cómo hacerla, aunque entonces se barajaba la posibilidad de la reconstrucción ideal, y en ese sentido se hacían estudios. No obstante, se tomaron ya una serie de medidas de consolidación (se recalzaron diversos muros del apodyterium, sudatorium y caldarium, se inmovilizó la base del muro este del tepidarium y se apuntalaron algunos pavimentos antiguos). Algunas de estas actuaciones pudieran ahora parecer opuestas al criterio definitivo (conservar estrictamente lo heredado), pero lo cierto es que eran inexcusables (por

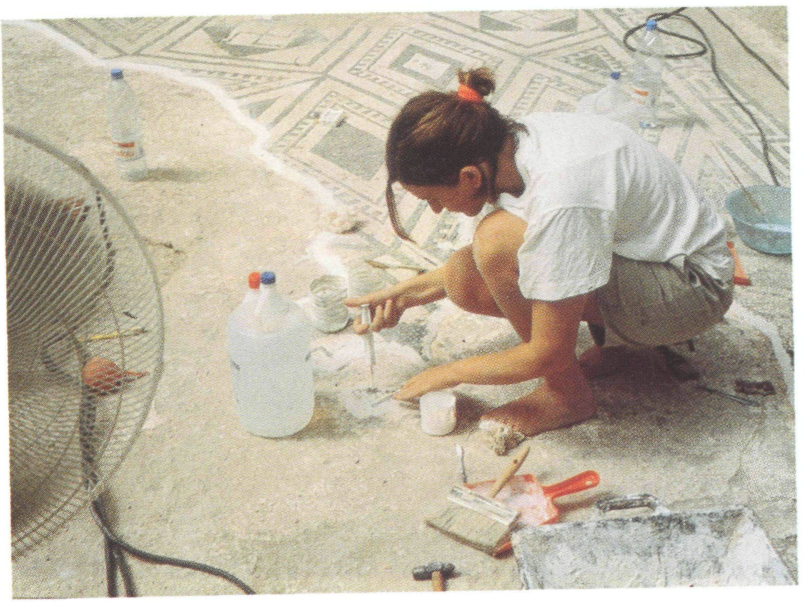

ejemplo, la recuperación de la superficie del apodyterium -en buena parte perdida-mediante un pavimento de mortero de cal y arena, sobre un forjado de viguetas pretensadas y revoltones, con una trampilla que permite el mantenimiento o la visita de la sala del pre-horno situada debajo).

Junto al muro que delimita superiormente el yacimiento, para detener la aportación lateral de humedad a éste, se hizo una trinchera de $60 \mathrm{~cm}$ y un muro de ladrillo hueco de medio pie, aislado con geotextil y lámina plástica con relieve. En otros puntos del yacimiento se construyeron pozos de drenaje.

Una vez decidido conservar los restos en su apariencia de ruina arquitectónica, lo que implicaba renunciar a cualquier intento de reconstrucción ideal o de purificación mediante la eliminación de restauraciones anteriores o de los desperfectos que la acción humana y el tiempo habían provocado, se acometieron los trabajos de consolidación de muros y de limpieza y restauración de revestimientos murales y de mosaicos.

\section{Consolidación de muros y revestimientos}

En la exploración de los restos, dificultada por una capa de suciedad que impedía distinguir los materiales, se detectaron sales en los muros (especialmente en los del frigi-

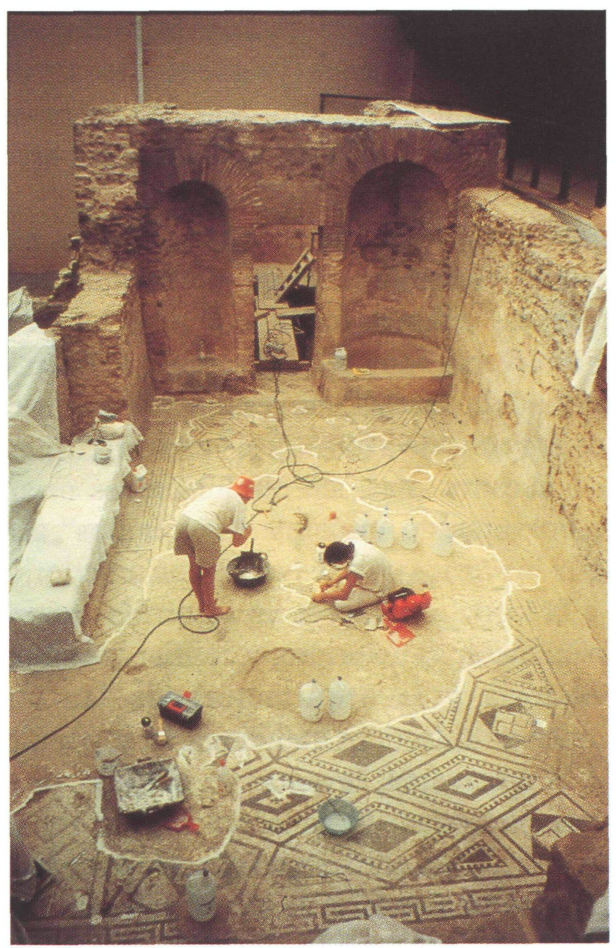

Proceso de consolidación del mosaico de teselas del frigidarium. Foto: Antoni González (GMN). Septiembre de 1998. 
darium y el tepidarium) y humedad por capilaridad, sobre todo en el suelo de este último. Más tarde, una vez iniciada la limpieza de los muros del caldarium y de la sudatio, se observó la existencia de hongos que, según el informe de la Facultad de Geología, no eran motivo de preocupación al haberse extinguido su ciclo.

La limpieza se hizo en dos fases. La primera fue mecánica, es decir, mediante palas, espátulas y paletinas para extraer la suciedad. El polvo levantado en el transcurso de la limpieza se eliminó con pinceles y cepillos, y con aspiradora. Por último se hizo una limpieza química, actuando sobre los pavimentos y los revoques de opus signinum con agua destilada y cepillos de uñas. La segunda operación fue eliminar las sales de las paredes con apósitos de pasta de celulosa con agua destilada. Se hicieron tres aplicaciones en el frigidarium y en el tepidarium. Se tomó a bofetón una capa de pasta de papel en los muros y, una vez seca, se arrancó con el objeto de arrastrar las sales. De cada aplicación se tomó una muestra para hacer, mediante conductímetros eléctricos, un análisis cuantitativo de las sales. Al desprenderse éstas, se pudo observar los materiales y colores de los muros. Los bordes de los revoques que no estaban bien fijados se biselaron con mortero de cal apagada y arena de silicio de 2 granulometrías con pigmentos minerales para ajustar mejor el color al original. Después de extraer las sales se pasó de nuevo la aspiradora y se taparon los muros y el suelo con geotextil, al no haber acabado aún la obra del edificio.

\section{Restauración de mosaicos}

Los mosaicos estaban muy deteriorados; faltaban muchas teselas y había diferentes biselados y reintegraciones de cementos (portland, rápido, escayola) de los años sesenta. Lo primero que se hizo fue retirar los elementos sobrepuestos y se comprobó que muchas teselas estaban despegadas del substrato. Para consolidarlas, se inyectó acetato de polivinilo disuelto en agua destilada al $50 \%$. A la vez se iban fijando las orillas del mosaico con un bisel de mortero de cal apagada y arena de silicio lavada (dos tipos de granulometrías: una más fina y otra más gruesa) en proporción 1:3. Una vez aplicado el bisel de los pavimentos, para facilitar la integración y uniformidad del color, se aplicó chorro de arena al acabado.

A continuación, se procedió a la limpieza mecánica con aspiradores, cepillos, torno de dentista y bisturí, con el objetivo de eliminar las manchas de mortero y las concreciones. Después se aplicó una limpieza química, a partir de agua destilada y jabón neutro. Esta intervención fue suficiente en todo el mosaico, excepto en la puerta que da al tepidarium. Se procedió a una limpieza con apósitos de sepiolita (arcilla hidrófila y detergente) y un $5 \%$ de triotelonamina (jabón), mezclado con agua destilada.

En cuanto a las lagunas, de acuerdo con el criterio general de intervención en los restos, no se previó la reintegración de las teselas y se trataron con mortero de cal.

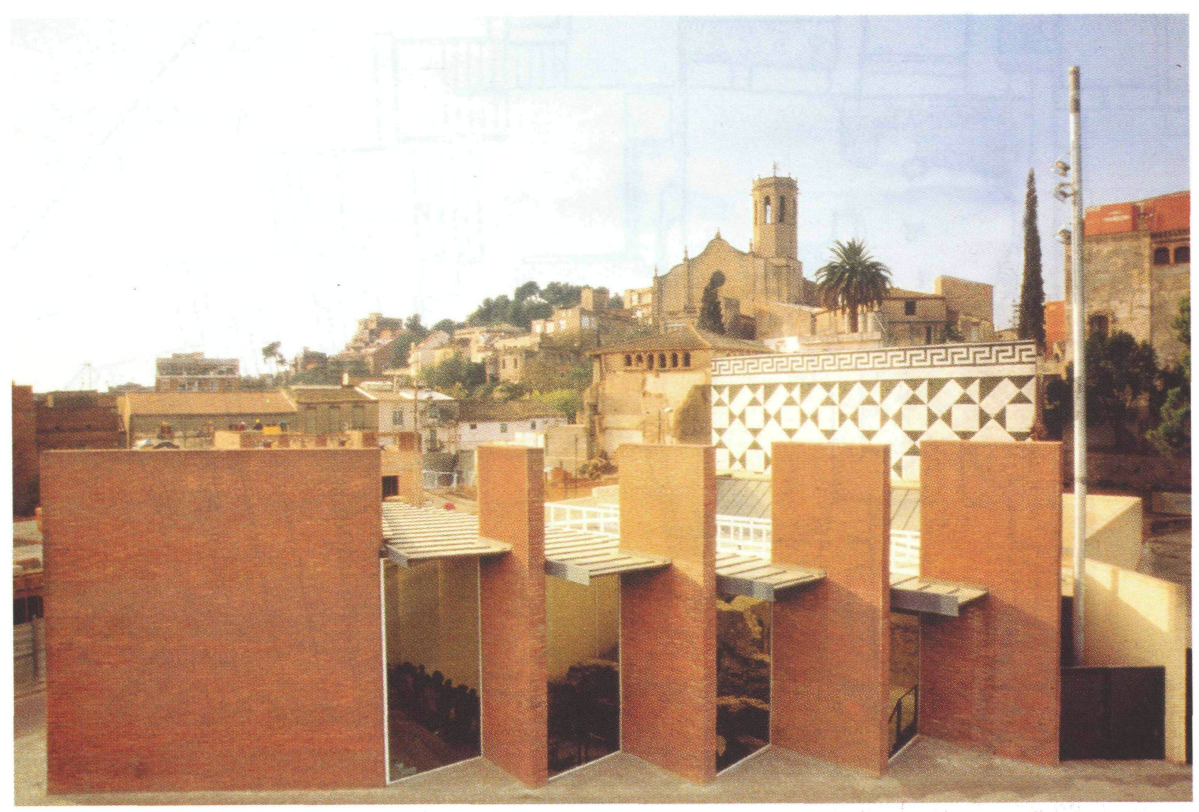

Vista del edificio desde el norte. En segundo término, el centro histórico de Sant Boi de Llobregat, presidido por la iglesia parroquial. Foto MBS. Octubre de 1998. 


\section{ELNUEVO EDIFICIODE PROTECCIÓN}

Como he dicho, los rasgos generales del edificio que había de cobijar los restos y facilitar la visita (rasgos que sufrieron variaciones importantes a lo largo del proceso de reflexión y proyecto) se concretaron así: debía consistir en una sala semi-abierta, espacialmente diáfana (y que permitiera el mayor grado de iluminación diurna natural posible), que envolviera los restos históricos (evitando el contacto con ellos, por razones formales y de indemnidad) y les diera el máximo protagonismo, y que salvara las especiales circunstancias topográficas del lugar (el yacimiento se encuentra en una cota entre 2 y 4 metros por debajo de la de la calle). En cuanto a su lenguaje expresivo, debía ser autónomo respecto de los restos (había que evitar toda contaminación historicista) y, respecto del entorno urbano, que fuera capaz de actuar como referente formal, tanto para publicitar su función y su contenido, como para ayudar a resignificar un tejido maltratado en su evolución reciente.

Un condicionante decisivo de la solución final, ya señaladopero que conviene destacar para entender correctamente ésta, fue el imprevisto aumento de superficie que el edificio sufriera cuando ya la obra empezaba su recta final de acuerdo con el proyecto inicial. En enero de 1998, el
Ayuntamiento de Sant Boi, para ubicar equipamientos culturales, adquirió el edificio conocido como Can Torrents, situado en la finca adyacente a la de las termas, rodeado de jardines colindantes con ésta. La nueva titularidad municipal de los espacios vecinos permitió replantear la línea divisoria de ambas parcelas e incorporar a la nuestra terreno suficiente en el que proyectar una ampliación del edificio en construcción que resolviera algunos problemas no del todo resueltos en el primer proyecto, en buena parte por la escasez de espacio entre los restos de las termas y la propiedad vecina (en la que incluso se adentraban algunos restos, como la piscina).

El proyecto de esta ampliación posibilitó redefinir la relación de los restos con el edificio (cuyo espacio se enriqueció notablemente), mejorar el recorrido de la visita, abrir una tercera puerta (apta para el acceso al recinto de personas discapacitadas) y un acceso directo a la cubierta para su mantenimiento, así como excavar y liberar los restos de la piscina. La redacción del nuevo proyecto también se aprovechó para tratar de subsanar algunos errores técnicos y de planteamiento del primer proyecto (especialmente, la cubierta, con serios problemas de estanquidad, y otros derivados de la falta de ventilación, lo que había obligado a una serie de estudios de climatización).

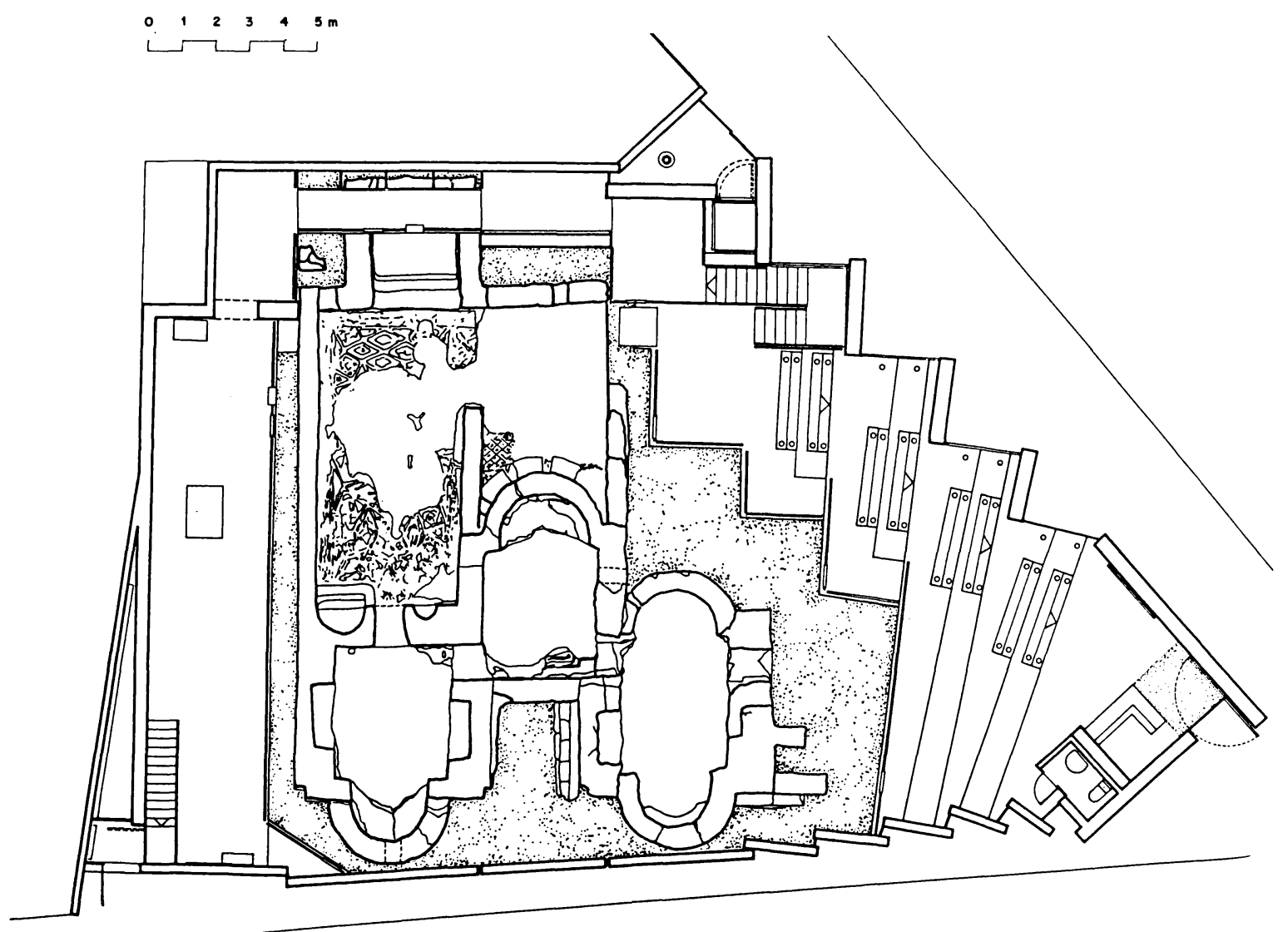

Planta general del edificio de protección y los los restos de las termas romanas. 


\section{Descripción del edificio}

El edificio, en su definición actual, tiene dos fachadas a la calle (a mediodía y levante), una al jardín municipal vecino, al norte, y una medianería con un edificio de viviendas, a poniente. Las tres fachadas están resueltas a base de lienzos ciegos de obra vista, en dos de ellas en disposición oblicua respecto a la alineación de las calles $\mathrm{y}$ alternados con cerramientos de vidrio (enmarcados con junquillos metálicos), que permiten la entrada de luz natural y la visión de las termas romanas desde el exterior. Los paramentos de las fachadas laterales son de ladrillo blanco amarillento (de $25 \times 12 \times 5 \mathrm{~cm}$ ) y los de la fachada principal, de ladrillo rojo manual (de formato catalán, de $29 \times 14 \times 5 \mathrm{~cm}$ ). Estos lienzos sobresalen de la línea de coronamiento de las cubiertas a manera de acroterio.

El muro medianero de poniente correspondiente al edificio de viviendas, mucho más alto que el nuestro, está doblado con un muro, que sobresale $50 \mathrm{~cm}$ por encima de aquél, para mejorar el aislamiento térmico y proteger de la lluvia el edificio vecino. El paramento externo presenta un revestimiento de estuco y pintura con dibujos geométricos y grecas, reproducción de un detalle del pavimento de mosaico romano conservado, que actúa como elemento publicitario e identificador en la trama, visible desde un amplio entorno.

Hay tres accesos directos al interior del edificio: el principal, situado en la confluencia de las dos calles, presenta junto a la puerta de vidrio un lienzo ciego de mayor altura que el resto de los paramentos, revestido de placas de mármol de tonalidades rosa, del tipo Arni-Viola, de $150 \times 150 \times 3 \mathrm{~cm}$. El segundo acceso (que actúa también como salida de emergencia) se encuentra en el extremo sudoeste y se cierra con puerta metálica. El tercero, situado junto a la medianería del jardín público vecino, está adaptado para el acceso a personas con discapacidades fisicas.

La construcción tiene unos $550 \mathrm{~m}^{2}$ de planta y la cubierta, desplegada en diferentes planos y niveles, se levanta hasta una altura máxima respecto a la rasante de los viales unos 5,5 m. Los restos arqueológicos ocupan $175 \mathrm{~m}^{2}$ aproximadamente, tienen casi tres metros de altura de promedio y están a unos cuatro metros por debajo de las rasantes perimetrales. El interior del edificio es un espacio único continuo que permite la visión constante, itinerante y panorámica de los restos de las termas.

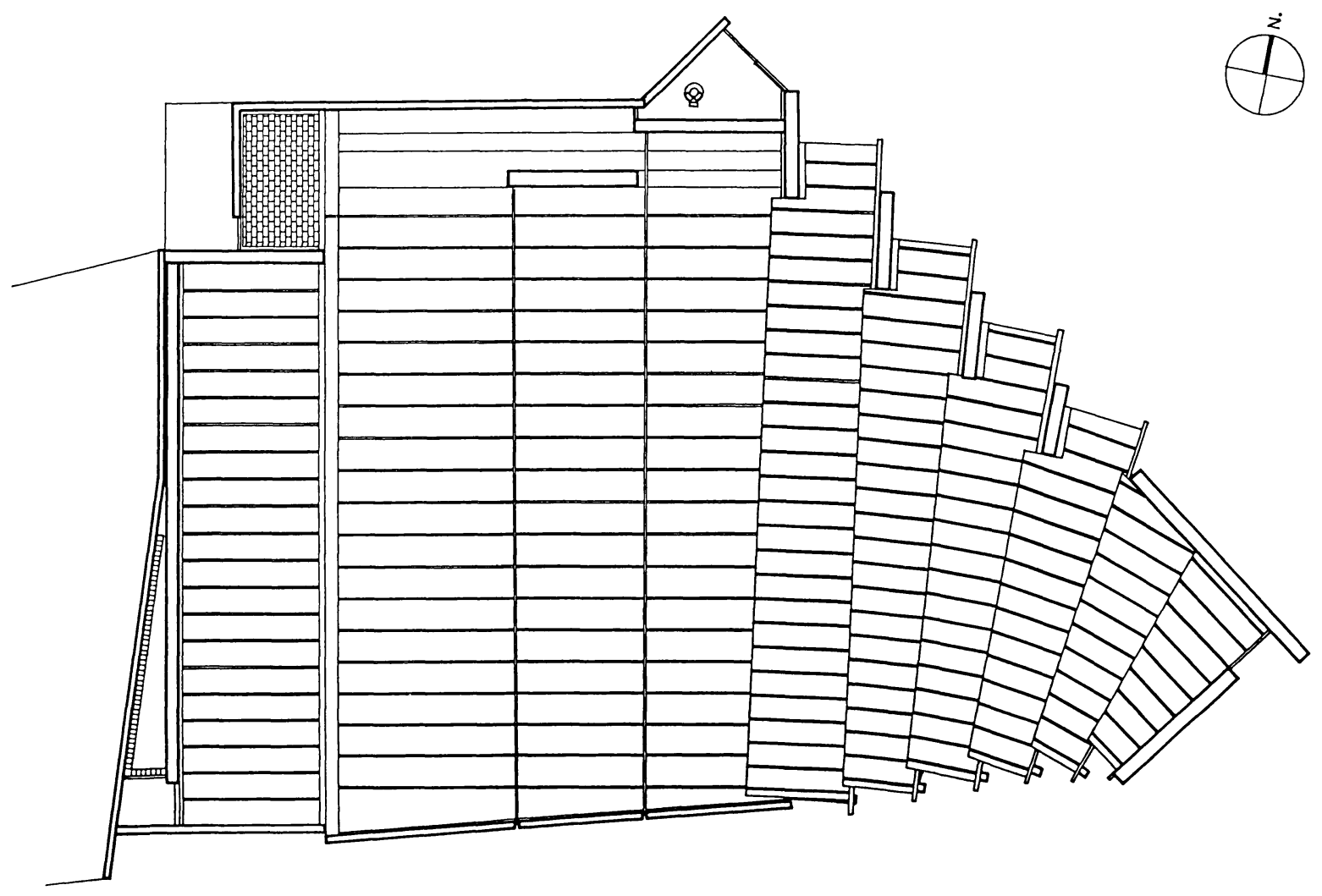

Edificio de protección de las termas romanas. Planta de las cubiertas. 
La cubierta de este espacio se desarrolla en tres tramos. El primero (el que cubre el acceso principal, el vestíbulo y las gradas), es un conjunto de paneles opacos, extendidos a modo de abanico escalonado y solapados a distinto nivel, lo que facilita la ventilación del espacio. El segundo, que corresponde a la parte central del edificio, es un plano inclinado translúcido, lo que permite la iluminación natural diurna y la artificial nocturna de los restos. El tercer tramo, también de una sola pendiente pero de sentido inverso (con la línea más alta entregada a la medianería), está resuelto con paneles opacos.

Por la entrada principal se accede, a pie llano, al vestíbulo y a las gradas por las que se desciende al nivel del yacimiento y desde las que éste puede ser contemplado en diversas perspectivas. En el extremo opuesto, junto a la medianería, se sitúa una sala rectangular, abierta hacia los restos, lo que permite su visión desde una altura intermedia. En el ángulo sudoeste de esta sala, un pequeño balcón triangular vuela para poder contemplar mejor aquel sector de las termas.

Entre el nivel inferior de las gradas, casi a la misma cota que la de los restos y esa sala intermedia discurre el recorrido lateral. Se inicia éste con una escalera que alcanza un nivel -a modo de balcón sobre los restos- del que parte una pasarela horizontal que conecta con aquella sala oeste. Desde ese nivel del balcón, una plataforma móvil permite el acceso y la salida de personas discapacitadas, que pueden continuar el recorrido a través de la pasarela.

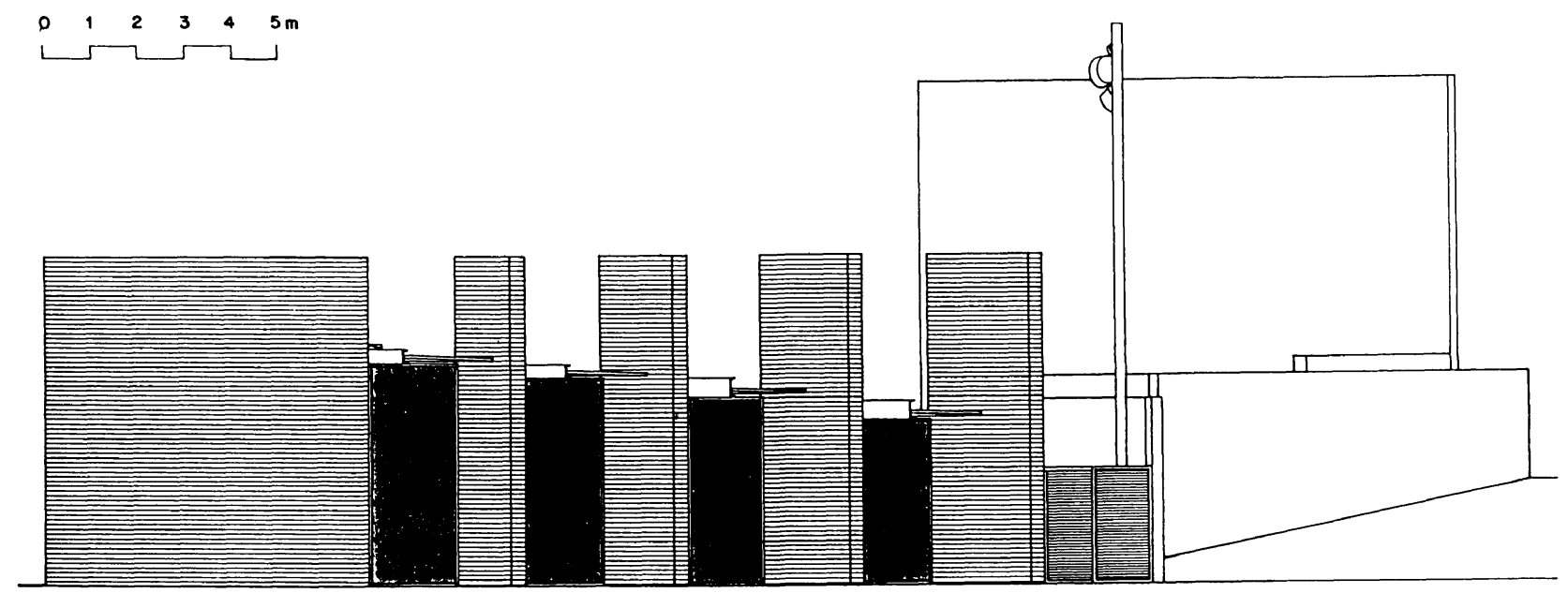

Alzado de la fachada norte.

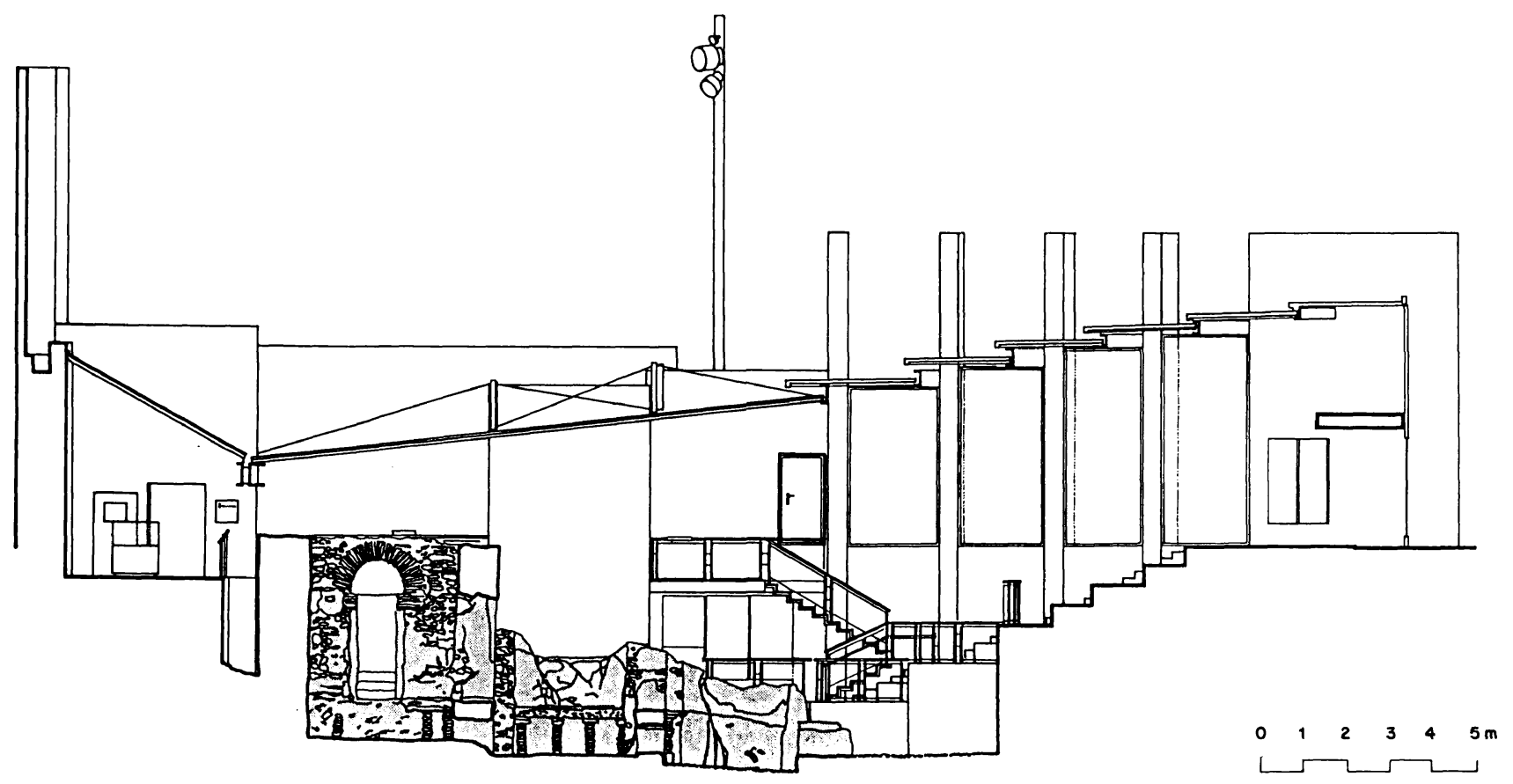




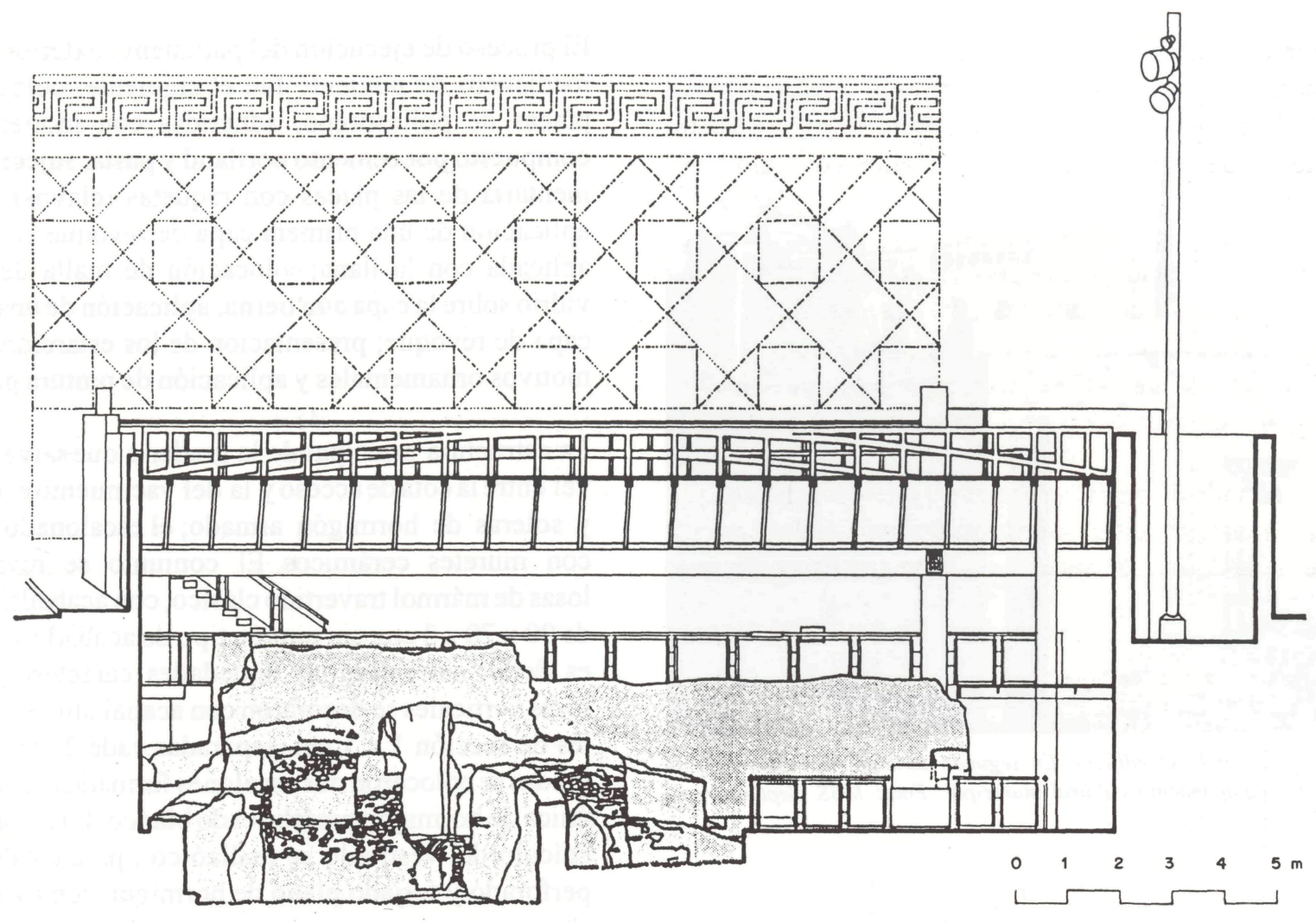

Sección norte-sur.

\section{La construcción del edificio}

Antes de comenzar las obras, los restos termales se protegieron: los mosaicos, con una capa de tierra de $8 \mathrm{~cm}$ y los muros, con tablero de madera. Después, en coordinación con el curso de la obra, se procedió a desmontar los restos de la antigua masía y del edificio protector del año 1964. Con el pertinente seguimiento arqueológico, se hicieron a continuación las excavaciones necesarias para construir las gradas y los diversos cimientos, y el rebaje de tierras a lo largo de la medianera de poniente.

Como el yacimiento está por debajo de las rasantes actuales, fue necesario construir muros de contención de tierras. En general, coinciden con los límites perimetrales de la obra y se convierten en fachadas al sobrepasar la rasante. Hay tres tipos de muros, en función del grosor y la resistencia requerida: de ladrillo macizo visto, de hormigón armado para chapear, y mixtos, de obra vista a dos caras y alma de hormigón. El vertido de éste se hizo por tongadas de escasa altura, para garantizar el correcto vibrado y la compactación.

El chapeado se hizo con pared de medio pie de ladrillo blanco o rojo según el caso, excepto un muro de contención de los años setenta que, como era más grueso, se chapeó con tira de ladrillo blanco. Con estos revestimientos, la

(c) Consejo Superior de Investigaciones Científicas

Licencia Creative Commons 3.0 España (by-nc) imagen interior de los paramentos es unitaria en toda su altura. Los lienzos situados bajo los ventanales exteriores se revistieron con baldosas de gresite de color blanco. Los muros que forman el vestíbulo de la entrada principal se estucaron con cal y arena de mármol extendida sobre el paramento revocado y con acabado de planchado en caliente. En el edículo de la conserjería algunos paramentos verticales, así como el mostrador y el cielo raso, se revistieron de tablero de aglomerado hidrófugo DM acabado con laminado plástico.

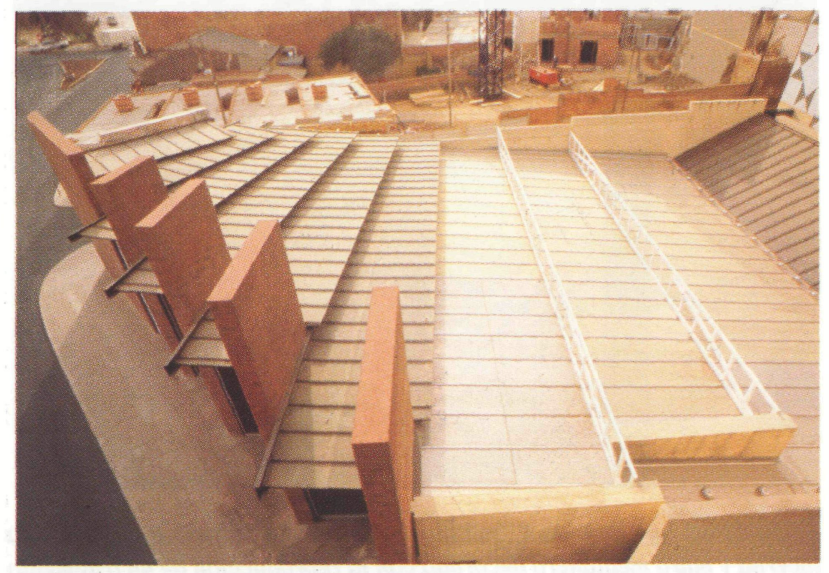

Vista exterior de la cubierta. Foto: MBS. Noviembre de 1998. http://informesdelaconstruccion.revistas.csic.es 


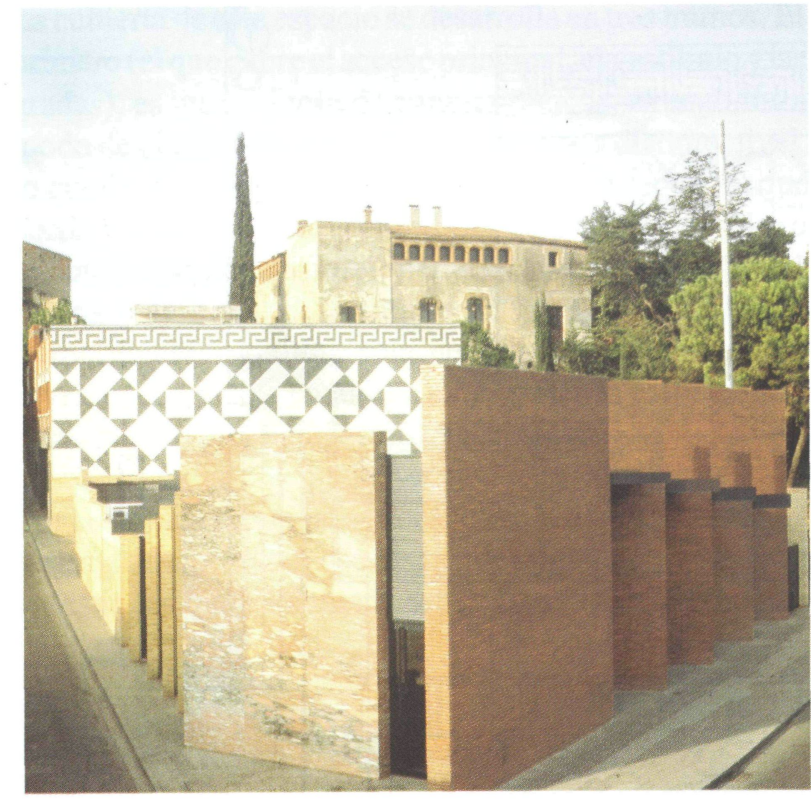

Acceso principal del edificio. En segundo término, la masia de Can Torrents, equipamiento cultural municipal. Foto: MBS. Septiembre de 1998.

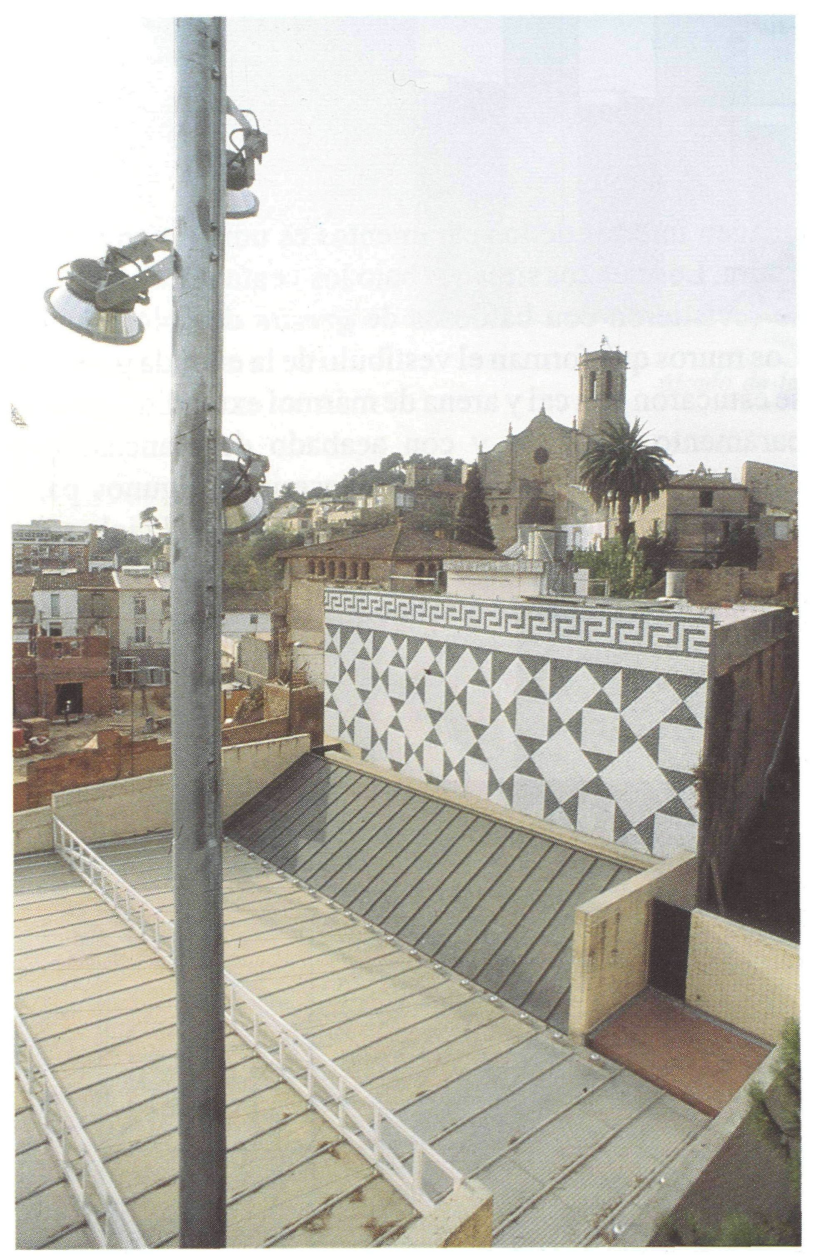

Torre de luz que ilumina de noche el interior del edificio a través de la lucerna y muro medianero decorado con la reproducción de un fragmento del mosaico. Foto: MBS Noviembre de 1998.
El proceso de ejecución del paramento exterior del muro medianero de poniente fue el siguiente: colocación de placas de poliestireno, adheridas con mortero mixto compuesto por cemento portland y pasta; sujeción suplementaria de las placas con raquetas (clavos) de PVC; aplicación de una primera capa de revoque con la pasta aplicada con la llana; colocación de malla de fibra de vidrio sobre la capa aún tierna; aplicación de una segunda capa de revoque; presentación de los estarcidos con los motivos ornamentales y aplicación de pintura plástica.

La estructura principal de la gradería que salva el desnivel entre la cota de acceso y la del yacimiento es de muros y soleras de hormigón armado; el escalonado se formó con muretes cerámicos. El conjunto se revistió con losas de mármol travertino clásico, con acabado de sierra, de $90 \times 70 \times 3 \mathrm{~cm}$, sin ningún tipo de acabado superficial, es decir, sin cerrar las oquedades características. Las losas verticales se decoraron con acanaladuras horizontales de sección $1 \times 1 \mathrm{~cm}$, separadas cada $2 \mathrm{~cm}$. Entre las gradas se colocaron dos escalones formados por una pieza única de hormigón prefabricado blanco. La estructura del edículo del vestíbulo se realizó con paredes de ladrillo perforado y forjado plano de hormigón con casetones.

El primer tramo de la cubierta se soporta sobre siete vigas (perfiles UPN) que apoyan sobre algunos muros y se anclan lateralmente por el alma a otros. Los paneles de cerramiento, cuya sección constructiva hubo que variar durante la ejecución de la obra, consisten en un tablero fenólico de $35 \mathrm{~mm}$ de grosor (que es el que se apoya sobre las correas de acero), una lámina de papel Kraff doble con brea intermedia $\mathrm{y}$, por encima, la lámina de cobre de $0,5 \mathrm{~mm}$ de grosor, colocada con el sistema belga (listón trapezoidal de madera).

La estructura metálica del segundo tramo, el plano inclinado translúcido, se formó con dos vigas (a modo de viga de celosía hechas a base de tubos rectangulares), que sobresalen del plano de cubierta, de las que cuelgan las correas, también de tubo rectangular de acero. La rigidez en la dirección perpendicular a las correas y la estabilidad en el plano vertical de las vigas se confió a tensores (varillas) cruzados de acero inoxidable. El material de cerramiento (tampoco bien definido en el primer proyecto, por lo que tuvo que ser redefinido y mejorado en el curso de la obra) es, en su mayor parte, de placas de policarbonato alveolar de $16 \mathrm{~mm}$, sujetas con perfiles atornillados a las correas, con junta longitudinal entre placas por solapamiento. En las zonas de este segundo tramo, fruto de la ampliación del edificio (que cubren áreas del recorrido, por lo que se decidió que no era necesario que fueran translúcidas), se utilizó panel sandwich autoportante compuesto por plancha que se puede pisar, de aluminio de $5 \mathrm{~mm}$ con relieve, más poliestireno extruido y chapa delgada de aluminio unipanel, lisa y visible desde el interior. Para incrementar la ventilación del espacio 
interior se colocaron, en algunos de estos plafones, extractores estáticos de fundición con deflectores de la escorrentía aguas arriba, todo de aluminio.

El tercer tramo de la cubierta, también de una sola pendiente $(57 \%)$ pero de sentido inverso a la del segundo (con la línea más alta entregada a la medianería), está resuelto, como el primer tramo, con paneles opacos revestidos por el exterior con lámina de cobre. Éste y el segundo tramo descansan sobre una viga en $U$, realizada con platabandas soldadas, que sirve, además, para esconder el canal de recogida de aguas, hecho de chapa doblada de cobre, que las lleva a las dos bajantes situadas en los extremos desde donde se vierten en el alcantarillado público.

El pavimento es, en general, de mármol travertino sin pulir, la mayor parte de piezas de $60 \times 40 \times 2 \mathrm{~cm}$; en la sala oeste fue colocado sobre lecho de grava y solera de hormigón. Los escalones de las gradas son de hormigón prefabricado visto. El pabellón de la conserjería y el lavabo es de baldosas de gres mate de $5 \times 5 \mathrm{~cm}$, colocadas a tendel con mortero adhesivo. La escalera que enlaza la sala oeste y la puerta suroeste es de peldaños independientes y en voladizo, de hormigón realizado in situ y dejado visto. Finalmente, los espacios libres entre los restos y la obra nueva se pavimentaron con gravilla de
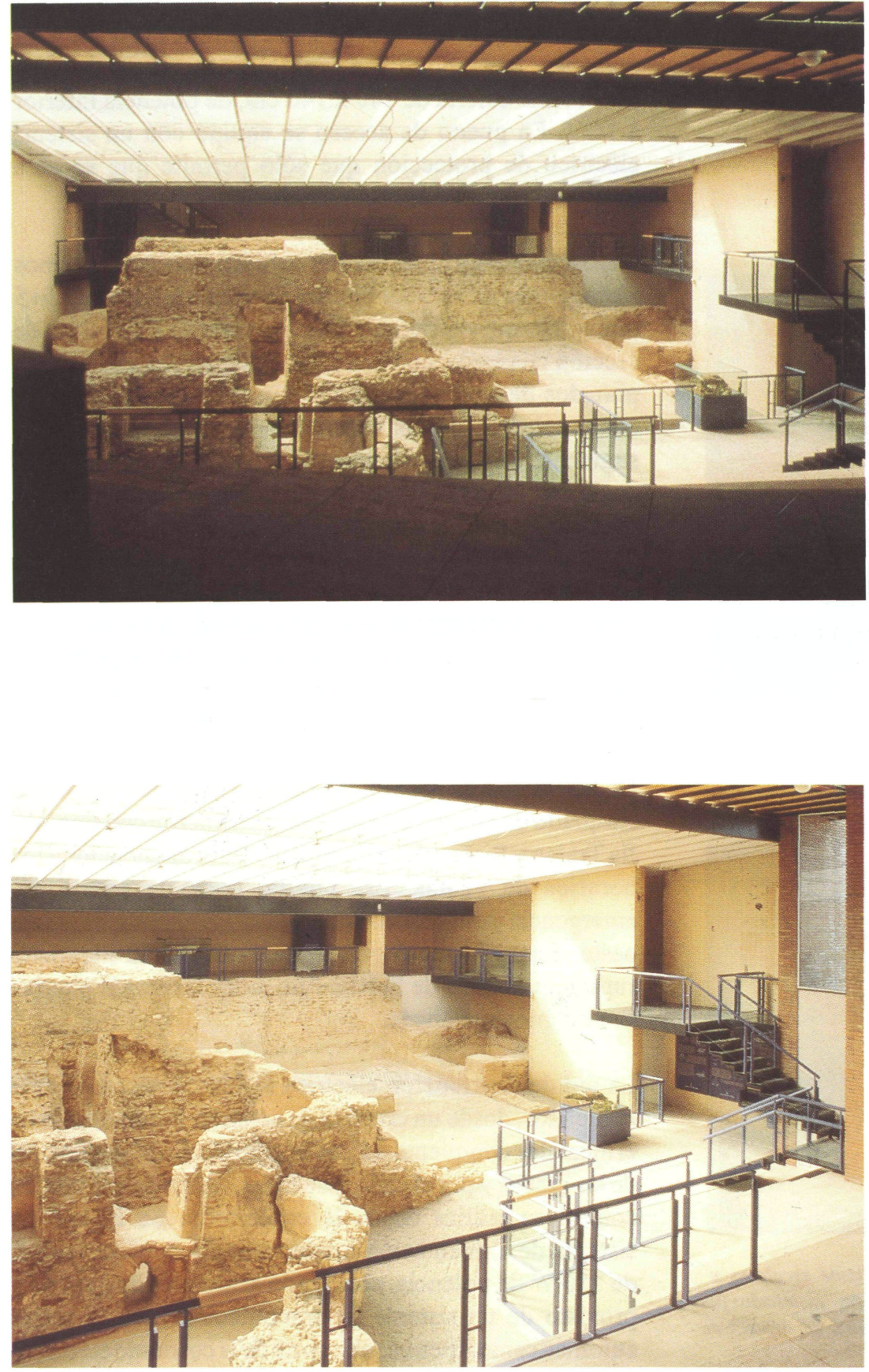

(c) Consejo Superior de Investigaciones Científicas Licencia Creative Commons 3.0 España (by-nc)
Primera visión que el espectador tiene de las termas al entrar por la puerta principal. Foto: GMN. Septiembre de 1998.
Vista del interior del edificio desde las gradas de acceso. Foto: MBS. Septiembre de 1998. 


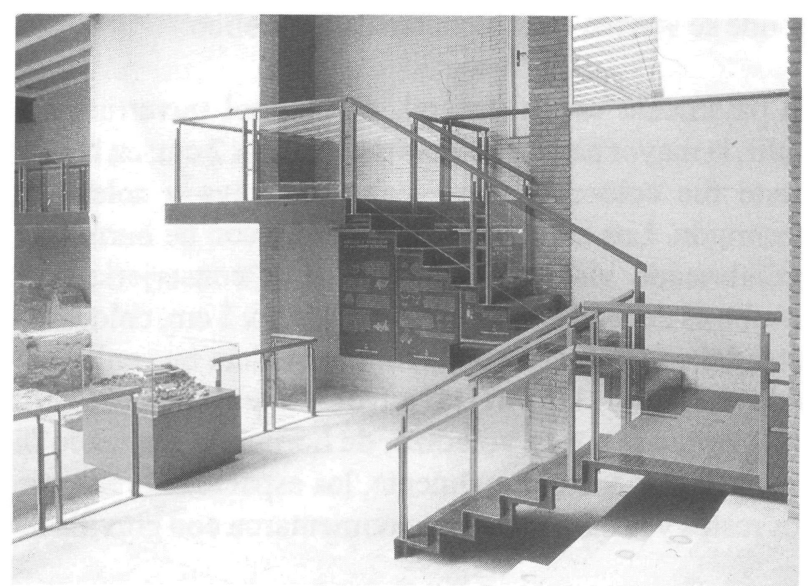

Escaleras de comunicación entre el nivel inferior de las gradas y la pasarela de acceso a la plataforma posterior. Foto: MBS. Septiembre 1998.
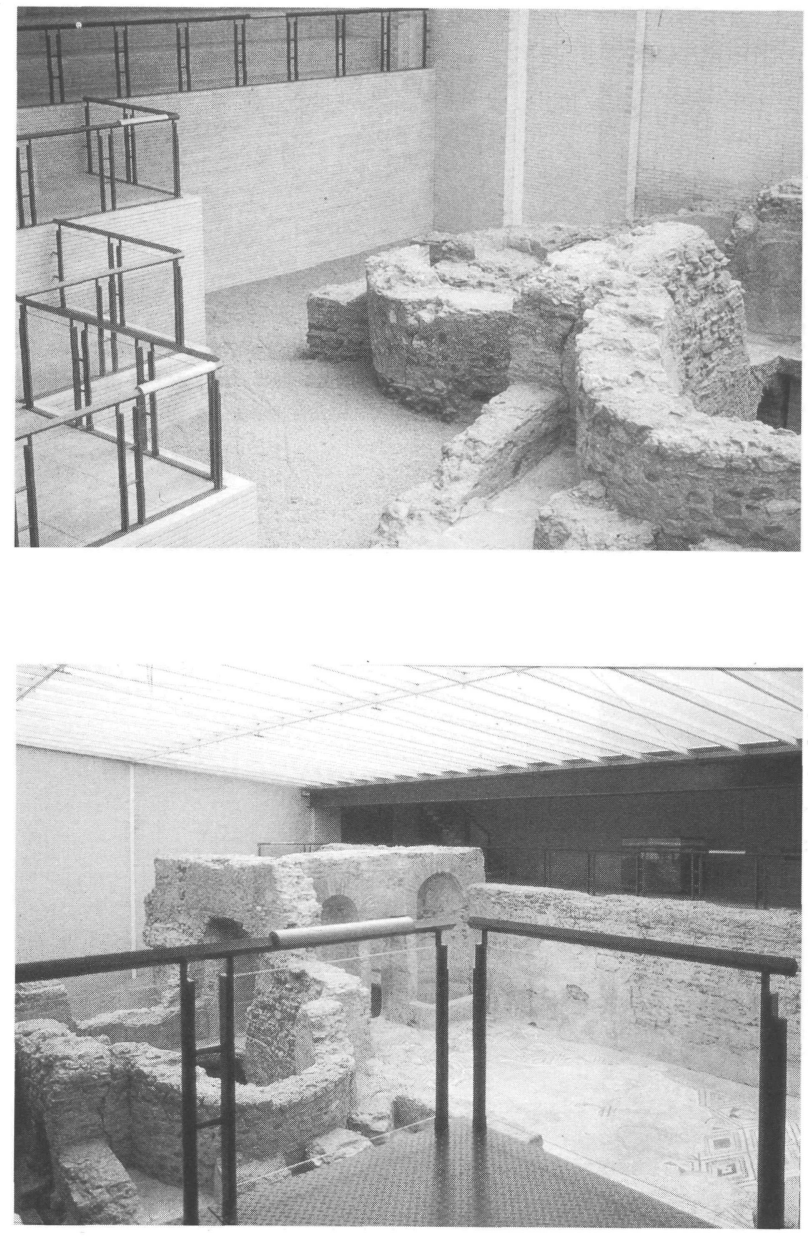

El recorrido perimetral de las termas, creado mediante escaleras y pasarelas, ofrece al espectador diferentes puntos de mira, insinuados por los posabrazos de madera de las barandillas. Foto: MBS. Septiembre de 1998.

(c) Consejo Superior de Investigaciones Científicas Licencia Creative Commons 3.0 España (by-nc) tipo ojo de perdiz, a modo de alfombra. En este sector se aplicó un tratamiento de desertización de la vegetación, de un año de duración activa, a base de un producto neutro que no agrede los materiales de los muros antiguos. También se aplicó un tratamiento raticida, en dos fases con un mes de diferencia.

La estructura de la pasarela y el balcón del recorrido de visita se realizó con pasamanos de 240 × $40 \mathrm{~mm}$ y rigidizadores (tensores) de $70 \times 20 \mathrm{~mm}$. El pavimento es de chapa de acero autoportante, con relieve, de $6 / 8 \mathrm{~mm}$ de grosor, pintada al esmalte. La estructura de la escalera es de tubo cuadrado y, los escalones, de la misma chapa. En el espacio de conexión entre la escalera y la pasarela, que sirve parcialmente como balcón, se instaló una plataforma que salva el desnivel de un metro aproximadamente que tiene respecto de la calle y que permite el acceso a las personas con movilidad reducida. Se trata de una plataforma abierta de $140 \times 140 \mathrm{~cm}$, de potencia inferior a $1 \mathrm{CV}$. La puerta de acceso se equipó con un sistema eléctrico de protección que sólo permite que se abra cuando la plataforma está a su nivel.

Las barandillas y protecciones se hicieron con pasamanos y montantes de acero y lienzos de vidrio laminar de 5+5 mm y lámina de butiral. Los pasamanos son tubos de sección cuadrada, con una de sus diagonales en vertical, pintados de azul pantone 534. En los lugares en que la contemplación de las ruinas resulta más explicativa o sugerente, hay reposabrazos de madera de haya barnizada de sección semicilíndrica para inducir al espectador a detenerse. Los montantes son macizos, de sección rectangular de $60 \times 20 \mathrm{~mm}$, anclados por la base a una pletina metálica horizontal recibida en la obra con tacos químicos de expansión, colocados a tresbolillo; en el caso en que los montantes descansaran sobre estructura metálica, se soldaron. Los lienzos de vidrio se fijaron a los montantes mediante perfiles de acero de sección en U.

De las puertas de acceso, la principal es de acero y vidrio templado de $10 \mathrm{~mm}$, en el que se inscribieron con tipografia Trajan y Sintax de color azul el rótulo anunciador y los horarios de visitas. Esa puerta, como la puerta de emergencia y una interior situada bajo el mirador de la sala oeste -éstas, de acero galvanizado- tienen un montante superior metálico de librillo fijo; todas las demás puertas son también metálicas.

La red de distribución eléctrica se hizo pasar, mediante entubados, desde un armario de acometida empotrado en el muro de cerramiento del jardín, por debajo del pavimento de las gradas y por el cielo raso del pabellón de entrada. El control se realiza desde la conserjería. Se instaló un sistema de alimentación ininterrumpida de electricidad, de $750 \mathrm{~W}$ de potencia, conectado al alumbrado general y provisto de un sistema de conmutación (que lo activa automáticamente en caso de corte de la corriente eléctrica) 
y reserva de carga. La instalación de agua corriente sigue el trazado de la eléctrica, por debajo del pavimento, y es de tubo de cobre. Tiene tres puntos de agua: uno en el lavabo, otro en la zona de las ruinas y un tercero en la cubierta.

La iluminación artificial se resolvió de manera diferente a la que se había previsto en el primer proyecto. La luz general procedente de un elemento exterior situado junto a la fachada del jardín, ilumina, a través de la lucerna, el espacio de los restos arqueológicos, como si reprodujese la luz natural; se trata de un báculo Prim de $16 \mathrm{~m}$ de altura, con tres focos de $1.000 \mathrm{~W}$ con visera para evitar la contaminación lumínica; esta iluminación se complementa desde el exterior con un bañador para el muro norte de halogenuros metálicos de $70 \mathrm{~W}$ y un aplique bajo Carandini empotrado en el muro opuesto. En el interior, enfatizando las gradas y sus escalones, se colocaron focos empotrados en el suelo y, en el muro situado junto a la pasarela metálica, seis apliques Kreon, también empotrados.

Los paneles explicativos tienen incorporada una luminaria longitudinal para facilitar su lectura. Las dos maquetas también tienen iluminación interior. Finalmente, empotrados en el falso techo del edículo del vestíbulo, cuatro focos halógenos pequeños remarcan el mostrador. La sala oeste queda sin alumbrado específico, al ser suficiente la procedente de las ruinas iluminadas. La luz de señalización se realizó mediante placas que indican los servicios y las salidas de emergencia.

El equipamiento contra incendios consiste en dos extintores de polvo seco de $12 \mathrm{~kg}$ y un extintor de anhídrido carbónico. También se realizó una instalación antiintrusismo con diversos detectores interiores, conectada telefónicamente con la policía municipal; los cableados se enterraron bajo los pavimentos y el control se situó en el edículo de conserjería. Posteriormente se añadió una sirena exterior.

Acabadas las obras del edificio, pronto se detectaron los problemas derivados del deficiente diseño de la cubierta, que no pudieron resolverse del todo en el curso de la obra.

No todos los errores pudieron ser resueltos totalmente, estando prevista para el año 2000 una revisión general de la obra, cuando, al año de haber entrado en uso, se tengan más datos sobre su comportamiento real. Para ello, con objeto de tener constancia de la temperatura y la humedad del interior del recinto a lo largo del año y los diferentes estadios de uso del edificio, se colocaron, en el verano de 1998, en cinco puntos estratégicos, aparatos termohigrógrafos con control remoto por ordenador, que han actuado durante el período de un año. Este estudio permitirá hacer las correcciones necesarias, en el caso que se demuestre que la realidad ambiental actual podía perjudicar la buena conservación del yacimiento o la comodidad de los visitantes.

(c) Consejo Superior de Investigaciones Científicas Licencia Creative Commons 3.0 España (by-nc)

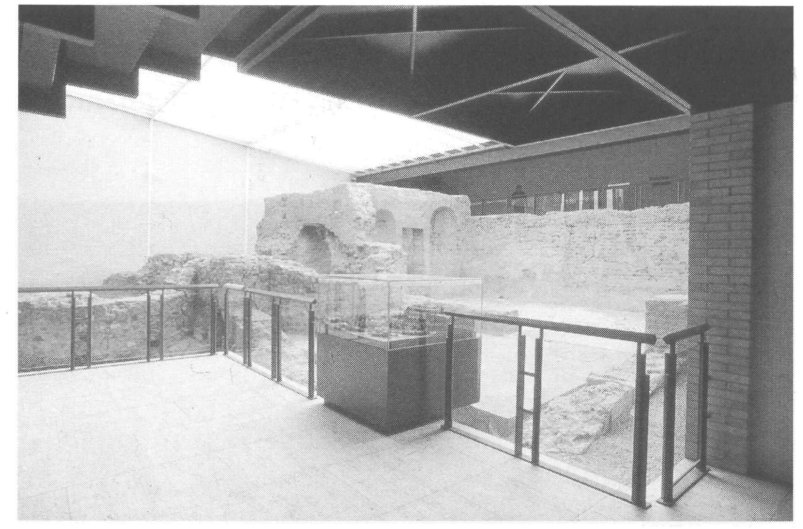

Visión de los restos de las termas desde el nivel inferior de las gradas. En primer término, maqueta de recreación ideal del paisaje de Sant Boi en época romana. Foto: MBS. Septiembre de 1998.

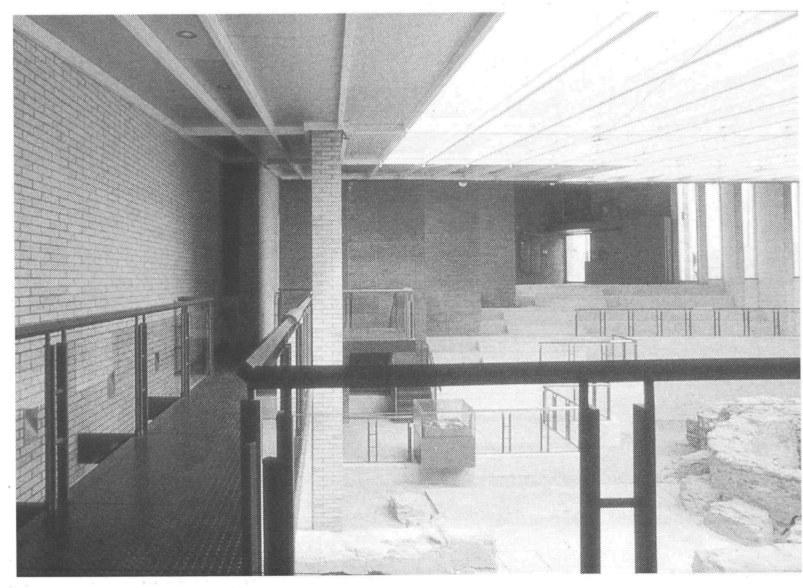

Visión de la plataforma elevada del sector de poniente. Foto: MBS Septiembre de 1998.

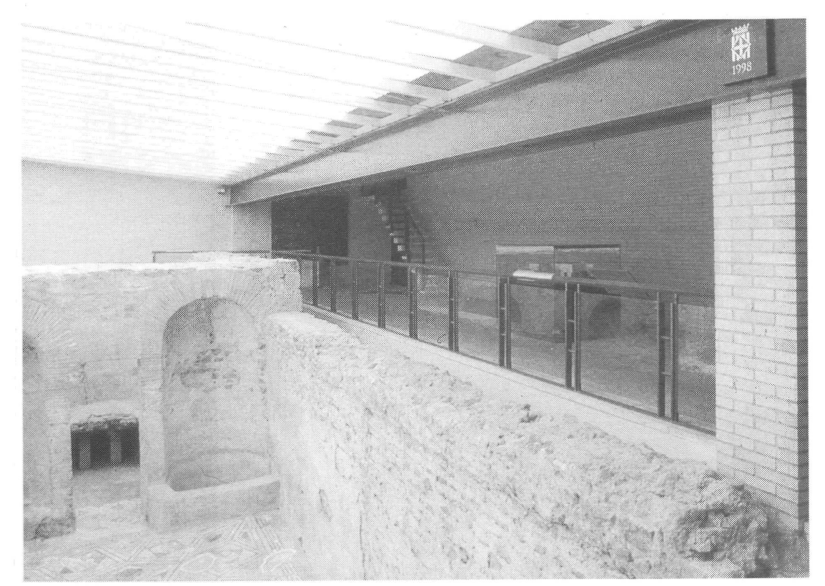

La plataforma superior vista desde la pasarela. En primer término, el frigidarium. Foto: MBS Septiembre de 1998.

http://informesdelaconstruccion.revistas.csic.es 


\section{LAMUSEIZACIÓN}

En cuanto a la presentación de las termas, se consideró esencial que los restos constituyesen en sí mismos el

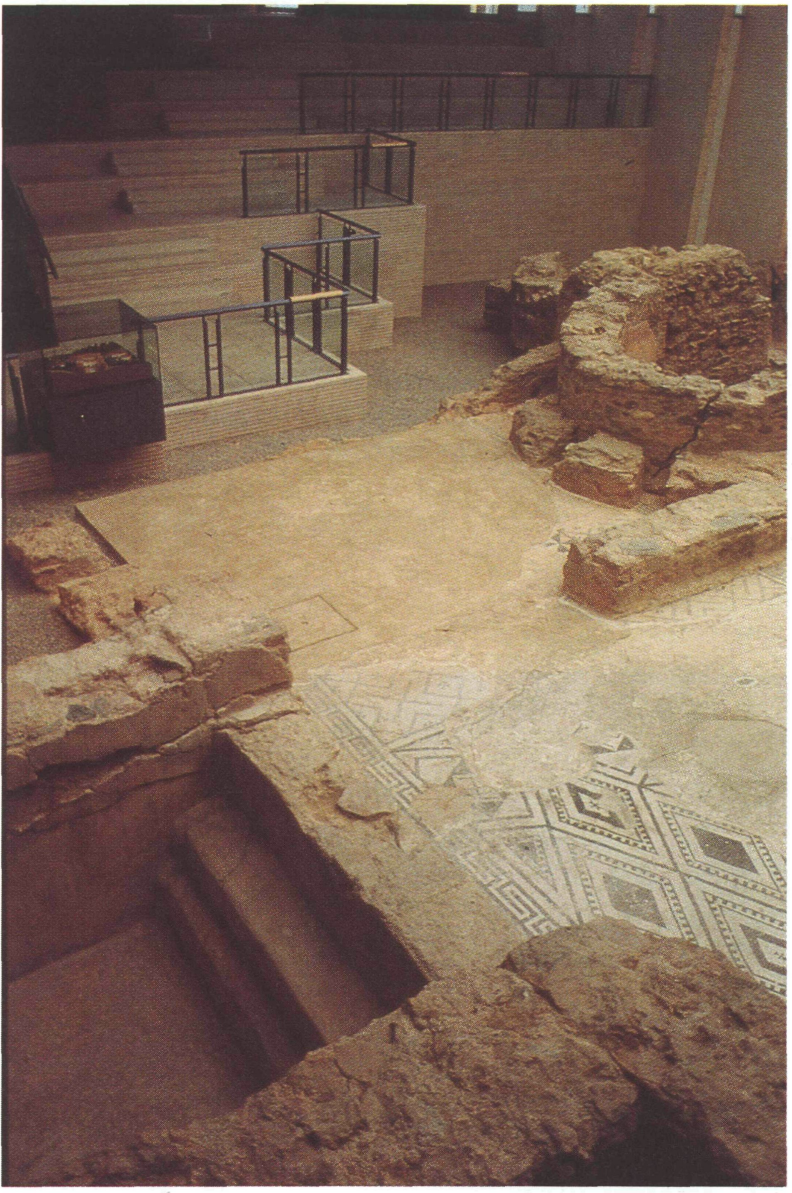

Aspecto de las termas una vez restauradas. En primer término, la piscina y el mosaico del frigidarium. Foto: MBS. Septiembre de 1998. elemento de primordial atracción del visitante sin que otros objetos o mecanismos distrajesen su atención; por ello decidimos prescindir de audiovisuales sofisticados, de realidad virtual o de cualquier otro tipo de aparatos o juegos, tan de moda ahora en este tipo de instalaciones. (Se corre el peligro de que esos artilugios pierdan su función de medio didáctico, para convertirse en finalidad en sí mismos, utilizados con fines propagandísticos o para incitar el consumo, razón por la que su uso satisface a tantos promotores culturales -que hacen de ellos bandera de modernidad-, falacia a la que arrastran a buena cantidad de deslumbrados profesionales.)

El programa museístico se resolvió, por lo tanto, con paneles informativos (los imprescindibles para explicar qué eran, significaban y cómo funcionaban las termas romanas y en especial las de Sant Boi), algunas vitrinas con materiales procedentes del yacimiento y dos maquetas. En cuanto al recorrido, como dije, se descartó efectuarlo por entre las ruinas (para evitar su degradación y porque los ingenios habituales diseñados para el acceso de los visitantes, además de costosos y de complicada adaptación, acaban por mistificar las ruinas cuya comprensión tratan de facilitar).

El guión perceptivo y emotivo del recorrido se estructuró así: en primer lugar, desde la misma entrada, el visitante descubre, con sorpresa y emoción, el volumen global de las ruinas. En aquel momento recibe una información mínima a través de plafones. Después, inicia una aproximación lenta hacia los restos, descendiendo por las gradas, desde cuyos cuatro niveles podrá ir variando los puntos de vista. Según el tipo de visita, se detendrá o no en esas gradas para recibir algún tipo de información oral. Al llegar a la cota más baja, el visitante, si lo desea, antes de proseguir, recibe una información más detallada mediante una maqueta y tres plafones. Inicia después el ascenso
Visión nocturna de las gradas del interior del edificio. Foto: MBS. Septiembre de 1998.

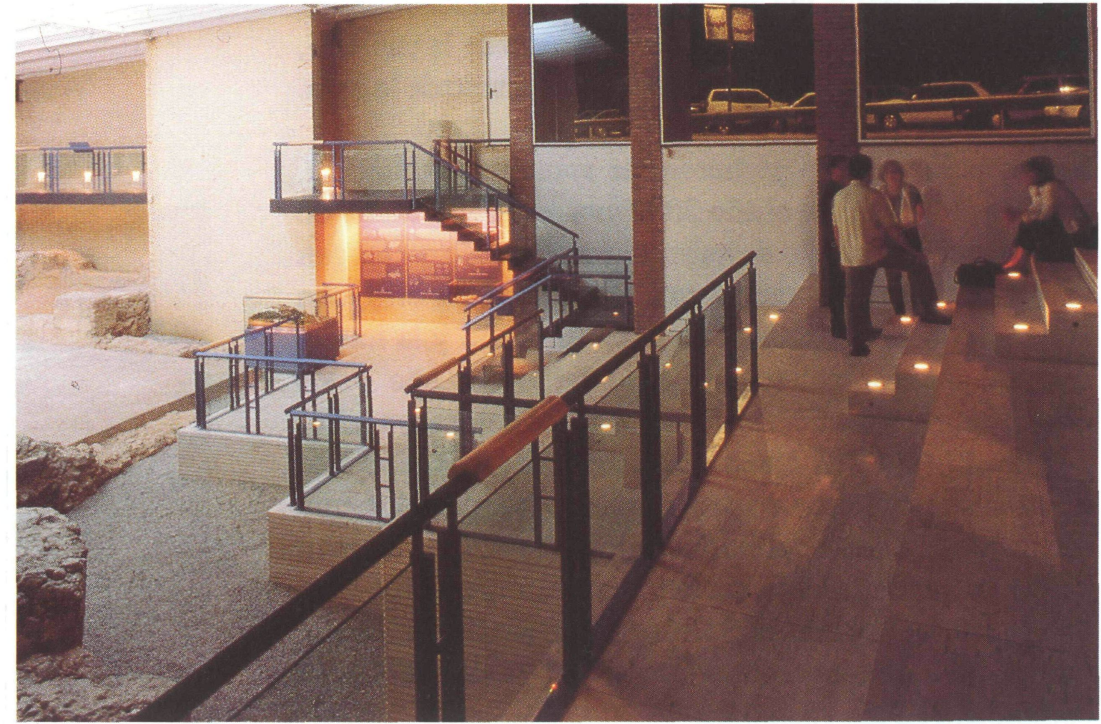

http://informesdelaconstruccion.revistas.csic.es 


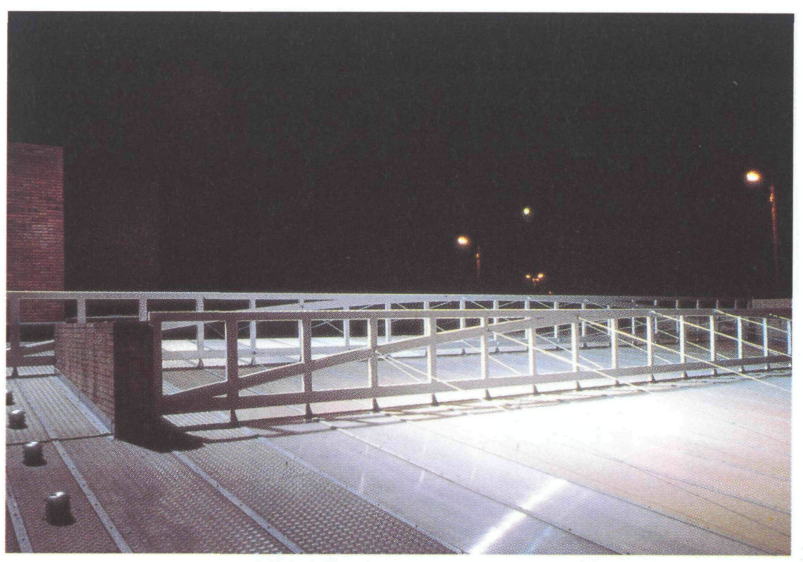

Visión nocturna de la cubierta del edificio de protección, iluminada. Foto: MBS. Septiembre de 1998.

hacia el balcón y, a través de la pasarela (disfrutando de nuevas perspectivas, algunas sugeridas mediante los reposabrazos) y recibiendo informaciones puntuales facilitadas en atriles, llega a la sala oeste, en la que puede recibir más información (una segunda maqueta, un audiovisual)y percibir perspectivas más próximas de las ruinas.

Y en cuanto al guión informativo se materializó así: los plafones situados a la entrada, titulados Sant Boi antes de Sant Boi y La investigación y la restauración, explican, mediante texto e ilustraciones, la aparición y formación del núcleo urbano de Sant Boi de Llobregat, y la historia del hallazgo y la restauración de las termas. La primera maqueta (colocada en una urna de vidrio laminado de $5+5 \mathrm{~mm}$ sobre base de plancha de acero esmaltado de $150 \times 150 \mathrm{~cm}$ ) reconstruye de forma idealizada el paisaje de Sant Boi en época romana, con la villa romana y sus termas, situado el edificio en idéntica orientación que las ruinas para que el espectador pueda comparar y comprender la transformación sufrida. De los plafones situados bajo el balcón, el primero informa sobre el origen, la evolución y las características de las termas, el segundo de las funciones y costumbres de los baños romanos y el tercero permite conocer su arquitectura. Las dos vitrinas contienen fragmentos de restos arquitectónicos y arqueológicos (mosaico, cornisa, cerámica, etc.) y objetos de uso cotidiano.

Desde lo alto del balcón, mirando hacia abajo, donde se encuentra la maqueta, el visitante puede apreciar aún mejor cómo era el territorio en la época de la construcción de las termas, cuyo volumen puede situar en la maqueta gracias al "usted está aquí", está señalado por un punto rojo sobre el vidrio laminado de protección. A lo largo del recorrido posterior, dos atriles de acero esmaltado, con textos y dibujos serigrafiados, muestran diferentes vistas de las termas (orientadas tal como éstas, para no confundir al espectador) indicando las salas de las que se componen. En la segunda maqueta se recrea el edificio termal cuando estaba en uso, seccionado, para que el visitante pueda comprender el funcionamiento de las diversas salas. $\mathrm{Al}$ final del itinerario, un panel informa de la actividad del centro productor de ánforas que existió en el lugar antes de la construcción de las termas, acompañado de una vitrina con fragmentos de ánforas encontrados en las excavaciones y la explicación de las marcas de los alfareros, y de un ánfora, recuperada y restaurada en los años sesenta, colgada en la pared sobre un panel. Todos los paneles están revestidos con planchas laminadas, de color azul (Pantone 534), y miden 192 x $100 \mathrm{~cm}$. La tipografía del fondo y del titular es la Trajan ( 4 y $10,5 \mathrm{~cm}$ ) y el texto Sintax (cuerpo 60). El texto de fondo, que contiene la leyenda Las Termas de Sant Boi y el título del panel, está serigrafiado en barniz brillante incoloro.

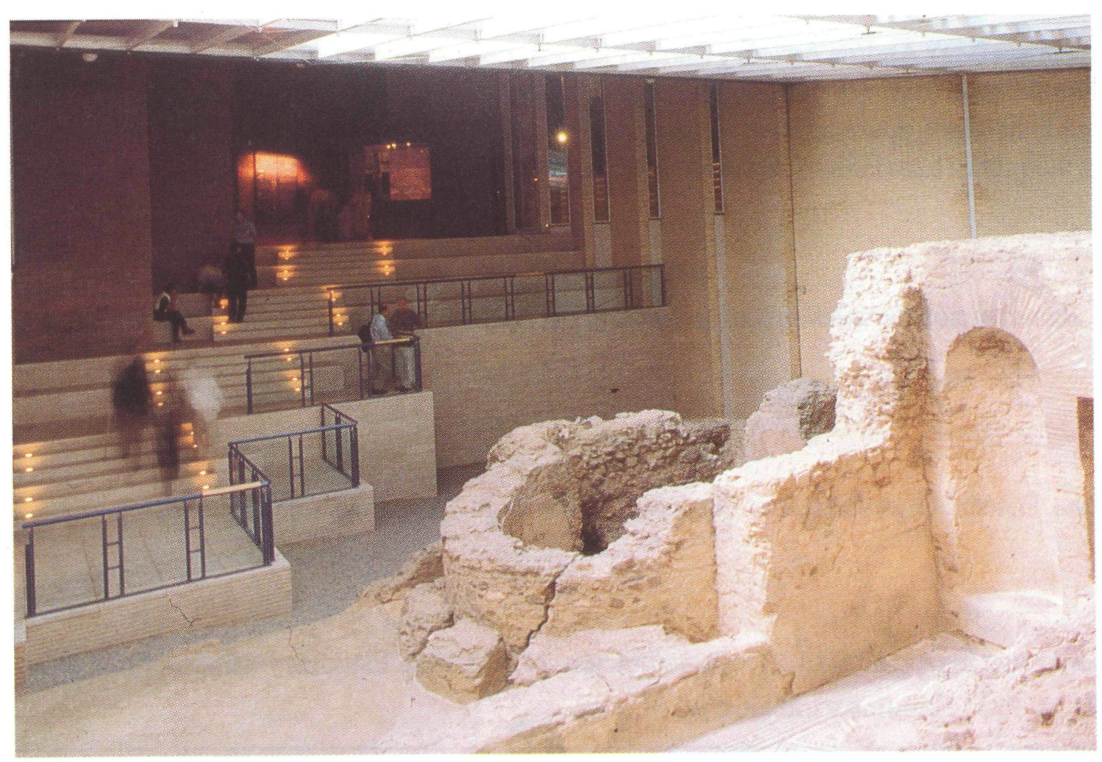

Visión nocturna del interior de las termas, bañadas por la luz procedente de la torre instalada en el exterior. Foto: MBS. Septiembre de 1998. 


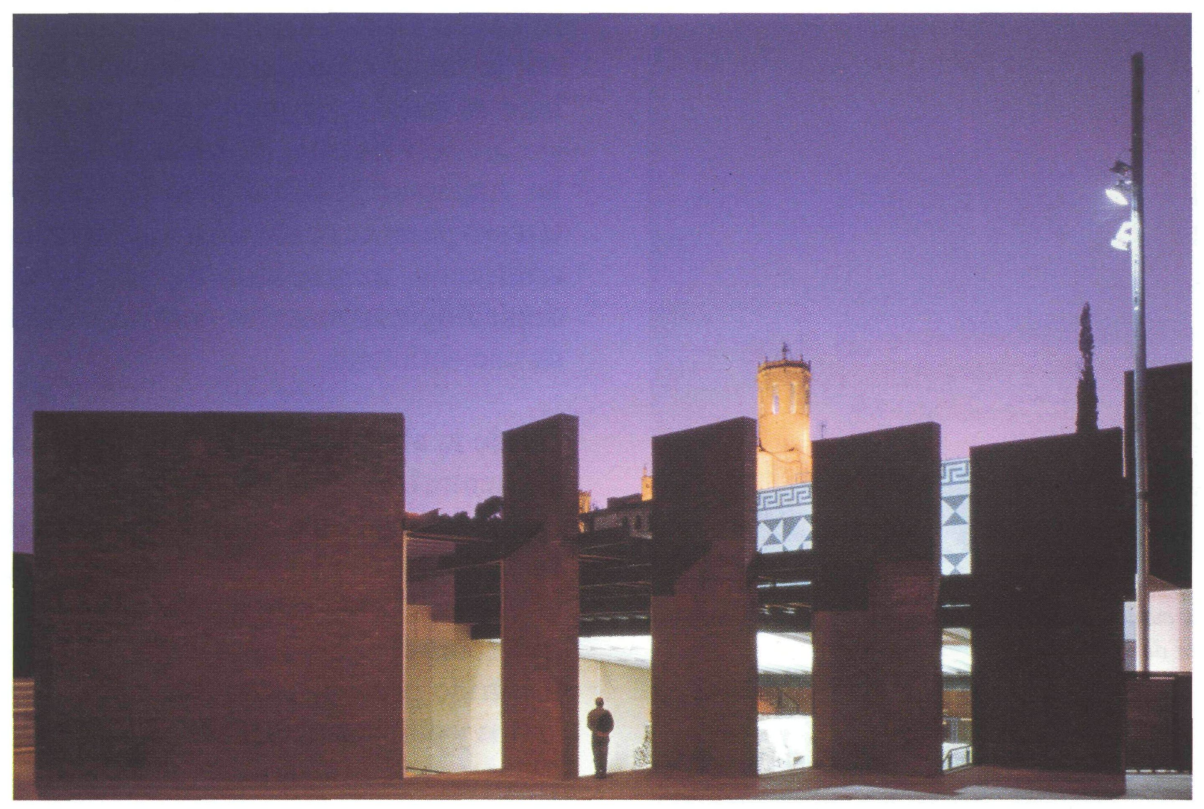

Visión nocturna desde el exterior. Foto: MBS. Septiembre de 1998.

\section{FICHA TÉCNICA}

Municipio: Sant Boi de Llobregat (comarca, Baix Llobregat; provincia de Barcelona).

Localización: calles del Hospital y de Maria Girona.

Actuación: promovida por el ayuntamiento de Sant Boi y realizada por el Servicio de Patrimonio Arquitectónico Local de la Diputación de Barcelona(1989-1998).

Trabajos de investigación histórica:

Estudio de fuentes documentales: Raquel Lacuesta; arqueología: Alberto López Mullor, Imma Estany, Xavier Fierro, Àlvar Caixal; numismática: Maria Clua; paleofauna: Lluís Rius; prospección geofísica: Lluís Marí, Josep M. Niñerola; estudio demateriales constructivos y sus patologías: Màrius Vendrell.

Edificio de nueva planta:

Idea general y primer proyecto (y dirección de la primera fase): Andreu Arriola y Carme Fiol, arquitectos; proyecto de mejora y ampliación: Antoni González, arquitecto; colaboradores: Pablo Carbó (director de la segunda fase), Josep Rovira, Josep Maria Sala, Sònia Blasco, arquitectos; Antonio Elizondo, Jaume Bassas y Albert Martí, aparejadores; Jacint Corderroure, maestro de obras; fotógrafa: Montserrat Baldomà; dibujantes: Txetxu Sanz, Jordi Serra; maquetas: Lars Höhne, Anna Álvaro.

Trabajos de consolidación de las termas:

Coordinación: Francisco J. Asarta, arquitecto. Restauración de revestimientos y mosaicos: Anna Cusó, Neus Zapata, Lourdes López, Margarita Alcobé, Marc Buchanan.

\section{Museización:}

Programa: Gregorio Gutiérrezy Raquel Lacuesta. Diseño: Olga de la Cruz. Grafismo: Quim Boix. Maquetas: Grau-Alcázar.

Inversión total: 238.000 .000 PTA.

Tratamiento de los restos: 53 M. PTA. Excavación arqueológica: 17,5 M. PTA. Restauración:24,5 M. PTA. Estudiosy trabajos: 11 M. PTA. Edificio de protección: 185 M. PTA. Obra: 165 M. PTA. Estudios y trabajos: 20 M. PTA. 